\title{
EL DERECHO INTERNACIONAL ANTE EL FENÓMENO BÉLICO: LA PREVENCIÓN Y ATENUACIÓN DE LAS CONSECUENCIAS DE LOS CONFLICTOS ARMADOS
}

\author{
José B. ACOSTA EsTÉVEZ*
}

RESUMEN: El derecho internacional humanitario es una rama o sector específico del derecho internacional público en tanto que responde a la sectorialización producida en su seno. Al igual que el derecho internacional del medio ambiente o el derecho internacional del espacio ultraterrestre, por citar algunos ejemplos, el derecho internacional humanitario, objetivamente, hace referencia a un sector especializado del ordenamiento jurídico internacional, y si bien es tributario de la teoría general de las fuentes del derecho internacional público, puede sostenerse su autonomía en tanto que integrado por un cuerpo específico de principios y normas internacionales para la protección de las víctimas de los conflictos armados, que es uno de los mayores retos que tiene que afrontar la sociedad internacional contemporánea. A este desafío responde esta rama del ordenamiento internacional.

ABSTRACT: International humanitarian law is specific a branch or sector of Public International Law as long as it responds to the subdivisions within it. Similarly to International environmental law or international space law, for instance, International Humanitarian Law objectively makes reference to a specialized sector of international legal order; and even when it pays tribute to the general theory of the sources of international law, it can keep its autonomy as long as it is integrated by a body of international principles and norms for the protection of victims of armed conflict, which is one off the main challenges contemporary international society has to face. This branch of international law responds to this challenge.

RÉSUMÉ: Le droit international humanitaire est une branche ou un secteur spécifique du Droit international public, répondant à la structuration qui s'est produite en son sein. En même temps que le droit international de l'environnement et le droit international spatial, pour citer quelques exemples, objectivement, le Droit international humanitaire fait référence à un secteur spécialisé des normes juridiques internationales et même s'il est tributaire de la théorie générale des sources du Droit international public, ce nouveau droit a une autonomie. C'est un droit intégré dans un corpus spécifique de principes et de normes internationales pour la protection des victimes des conflits armés, ce qui constitue un des défis que la société internationale contemporaine doit affronter. C'est à ces enjeux que le droit international humanitaire doit répondre.

* Profesor titular de derecho internacional público y relaciones internacionales. 
SUMARIO: I. Introducción. II. La prohibición del uso de la fuerza y la reglamentación internacional de los conflictos armados. III. El ámbito de aplicación de la normativa. IV. Los objetivos militares. V. Los medios y métodos de combate. VI. La protección de las víctimas de los conflictos armados. VII. La protección de los bienes culturales. VIII. La protección del medio ambiente. IX. La aplicación del derecho internacional humanitario. X. El control de la aplicación del derecho internacional humanitario.

\section{INTRODUCCIÓN}

La preocupación por las consecuencias de los conflictos armados, especialmente sobre la población civil, es una constante de los ideales humanitarios. Al respecto, la obra de Henry Dunant publicada en 1862, Un souvenir de Solferino, no sólo propició la idea de la Cruz Roja, sino que fue un importante acicate para la posterior elaboración de tratados internacionales multilaterales en la materia. Empero, no es el propósito de estas páginas recoger de forma pormenorizada el origen y la evolución operada en sede iusinternacionalista, tarea más propia de un tratado.

Dentro de los límites espaciales propios de un artículo se ofrece una visión de conjunto del derecho internacional humanitario (expresión preferida a derecho humanitario bélico), que trata específicamente de la protección de las víctimas de la guerra, con el fin de constatar si dicho derecho, tal como apuntó en 1959 Pastor Ridruejo, ${ }^{1}$ constituye un derecho de carácter suprainternacional. Dicho con otras palabras, la cuestión estriba en examinar este conjunto normativo para establecer su posible autonomía y diferenciación respecto del derecho internacional público. No cabe la menor duda de que se trata de una idea altamente sugestiva para todo iusinternacionalista, aunque se trate en principio de una construcción realizada a nivel teórico.

El supuesto carácter suprainternacional del derecho internacional humanitario vendría apoyado en tres circunstancias muy concretas, a saber: 1) Se trata de un derecho que vincula a sujetos que no son de forma necesaria miembros de la sociedad internacional; piénsese, por ejemplo, en los

1 Pastor Ridruejo, J., "Contribución al estudio del derecho humanitario bélico: concepto, contenido y naturaleza”, Revista Española de Derecho Militar, núm. 7, 1957, p. 70; e id., La protección a la población civil en tiempo de guerra, Zaragoza, 1959. 
rebeldes a los que no se les reconoce el status de beligerantes en un conflicto armado interno. 2) Se trata de un derecho que dispone derechos subjetivos a favor de la persona humana (titular de derechos), es decir, el individuo no reviste la categoría de sujeto de derecho internacional, pero es destinatario de normas internacionales humanitarias. Asimismo, atendiendo a la otra cara de la moneda, el individuo es destinatario de obligaciones internacionales, que pueden conllevar responsabilidad individual internacional penal. 3) Se trata de un derecho que estipula obligaciones para los Estados — sujetos de derecho internacional- respecto a sus propios nacionales y, sobre este punto, no hay que obviar que el mismo Comité Internacional de la Cruz Roja ha declarado que "también se puede admitir que se trata de un derecho internacional de un modelo nuevo por el que los Estados, por razones humanitarias, han aceptado ligarse a sí mismos, en algunas circunstancias, con respecto a sus propios ciudadanos". ${ }^{2}$ Por consiguiente, de acuerdo con la consecución de tal objetivo, se requiere una visión panorámica previa del derecho internacional humanitario y a partir de la misma podrá llegarse a la consideración o no de su carácter suprainternacional y, en consecuencia, afirmar su autonomía y distinción del derecho internacional público.

A nuestro juicio, el derecho internacional humanitario es una rama o sector específico del derecho internacional público; esto es, un conjunto de principios y normas internacionales para la protección de las víctimas de los conflictos armados. Nos encontramos, pues, en presencia de una rama del ordenamiento jurídico internacional referida a un sector específico de la realidad internacional. Asimismo, si bien es cierto que el derecho internacional humanitario es tributario de la teoría general de las fuentes del derecho internacional, no es menos cierto que detenta una autonomía normativa. En la actualidad, es indiscutible la existencia de un corpus iuris específico de normas internacionales para la protección de las personas - ampliado al medio ambiente y bienes culturales - en tiempos de guerra (dimensión internacional de la protección de la persona en los conflictos armados).

En atención al objetivo perseguido, la constatación del derecho internacional humanitario como un sector específico del ordenamiento jurídico internacional, la estructura del presente trabajo se articula en torno a

2 Comité Internacional de la Cruz Roja, Curso de cinco lecciones sobre los Convenios de Ginebra, Ginebra, 1962, pp. 15 y 16. 
nueve apartados. El primero versa sobre la prohibición jurídica del uso de la fuerza armada en las relaciones internacionales, y en él se establece brevemente un planteamiento general o estado de la cuestión: tal prohibición no es suficiente para evitar los conflictos armados y, de ahí, la vigencia del derecho internacional humanitario en tanto que derecho destinado a la prevención y atenuación de las consecuencias derivadas del fenómeno bélico. Este derecho nos acerca a la realidad de las cosas: la guerra puede estar prohibida y ser denostada, pero cada día se habla de sus víctimas. Se trata, por consiguiente, de un derecho necesario que debe ser reafirmado y desarrollado constantemente.

Tras una breve referencia al ámbito de aplicación en el apartado segundo, el tercero trata de los llamados objetivos militares desde la perspectiva de que las necesidades militares deben conciliarse con las consideraciones de humanidad indispensables en tiempo de guerra. En íntima relación se encuentra el apartado cuarto relativo a los medios y métodos de combate no susceptibles de ser utilizados por los beligerantes durante la contienda. De acuerdo con estos dos apartados puede aseverarse lo siguiente: desde un plano doctrinal se ha distinguido entre el derecho de La Haya (derecho de los conflictos armados), o regulación de los medios y modos de hacer la guerra, y el derecho de Ginebra (derecho internacional humanitario), referido a la protección de las víctimas de los conflictos armados. En el ámbito teórico tal distinción es esclarecedora e incluso pertinente desde un punto de vista docente, pero en el ámbito práctico es puro artificio. Las disposiciones contenidas en el derecho de La Haya y en el de Ginebra no sólo se fundamentan en los mismos principios, sino que además tienen una finalidad común. ${ }^{3}$

La afirmación realizada in fine se manifiesta plenamente en los apartados 5 a 7, relativos a la protección de las víctimas de los conflictos armados. El llamado derecho de Ginebra, a la hora de proteger a las víctimas, contiene numerosas disposiciones relativas al modo en que los combatientes deben conducir las hostilidades. Así, cabe concluir, que tanto este derecho como el de La Haya tienen como fin tutelar los intereses de las personas. Y si se da un paso más, puede observarse que en último 
extremo se están amparando los derechos humanos: ${ }^{4}$ en determinadas zonas el derecho internacional humanitario se solapa con el derecho de los derechos humanos, piénsese como botón de muestra los principios y las normas para la prevención y represión del genocidio, aplicables en cualquier circunstancia. Por otra parte, realizada esta matización, en la esfera de las víctimas se incluye no sólo a la persona humana, sino también los bienes culturales y el medio ambiente, pues no es ocioso recordar que tanto los unos como el otro son en la mayoría de las ocasiones "objetivo" de ataques.

El apartado octavo versa sobre la aplicación de las normas internacionales humanitarias. Obviamente, la existencia de estas normas deben ir acompañadas de unos mecanismos de aplicación que garanticen su efectividad, pues, en caso contrario, se estaría en presencia de una regulación ideal pero no real. Asimismo, en el apartado noveno se trata del control de la aplicación del derecho internacional humanitario. La cuestión es básica, pues la efectividad del mismo dependerá en gran medida del control de su observancia. Como señala Pastor Ridruejo, ${ }^{5}$ el gran problema radica en que no hay posiblemente destinatario más difícil y peor predispuesto al cumplimiento de las normas jurídicas que un beligerante obsesionado por la idea de evitar la derrota o alcanzar la victoria, pues como decía Séneca "las armas no tienen moderación; no es fácil aplacar ni contener la cólera de una espada, una vez desenvainada" (Hercules Furens, 403) y, por esto, en muchas ocasiones Cicerón afirmaba que "entre las armas las leyes enmudecen” (Pro Milone, 4,10). El uso de la fuerza armada, lícito ${ }^{6} \mathrm{o}$ no, es inhumano y la aplicación de las normas internacionales, en un intento de humanizarla, es una cuestión altamente problemática, y por extensión su control no es tarea fácil.

4 Al respecto, Gross Espiell, H., "Derechos humanos, derecho internacional humanitario y derecho internacional de los refugiados", en varios autores, Etudes et essais sur le Droit international humanitaire et sur les principes de la Croix Rouge, Ginebra, 1984, pp. 699 y ss.

5 Pastor Ridruejo, J., Curso de derecho internacional público y organizaciones internacionales, Madrid, 2001, p. 647.

6 Al amparo de alguna de las excepciones que admite el derecho internacional (sistema de seguridad colectiva, legítima defensa, situaciones coloniales). 


\section{LA PROHIBICIÓN DEL USO DE LA FUERZA Y LA REGLAMENTACIÓN INTERNACIONAL DE LOS CONFLICTOS ARMADOS}

A lo largo de toda la historia de la humanidad se puede comprobar que el recurso a la guerra era admitido como un medio de solución lícito de los conflictos existentes entre los Estados. Sin embargo, la situación descrita cambió a partir de 1945 cuando el uso de la fuerza fue proscrito por una norma imperativa del derecho internacional (artículo 2.4 de la Carta de las Naciones Unidas). ${ }^{7}$ Así, en el derecho internacional contemporáneo rige el principio de prohibición del uso de la fuerza en las relaciones internacionales, ${ }^{8} \mathrm{y}$ por esto:

Cabe afirmar categóricamente que está vigente una norma fundamental del derecho internacional general según la cual está prohibido que los Estados utilicen la fuerza armada para la solución de sus controversias... Tal norma es además imperativa en el sentido de que ha sido aceptada y reconocida como tal por la comunidad internacional de Estados en su conjunto, no admitiendo acuerdo en contrario y no pudiendo ser modificada o derogada más que por otra que tenga idéntica naturaleza. ${ }^{9}$

Sin embargo, a pesar de esta prohibición, los conflictos armados siguen existiendo en nuestros días y, por esto, una parte del derecho internacional público, denominado derecho internacional humanitario, ${ }^{10}$ apa-

7 Sobre el carácter de norma consuetudinaria de la prohibición del uso de la fuerza, véase sentencia del TIJ: CIJ, "Asunto concerniente a las actividades militares y paramilitares en Nicaragua y contra ella”, Recueil, 1986, pp. 96 y ss.

8 Bermejo García, R., El marco jurídico internacional en materia de uso de la fuerza: ambigüedades y límites, Madrid, 1993; Brownlie, I., International law and the use of force by States, Oxford, 1991; Gutiérrez Espada, C., El uso de la fuerza y el derecho internacional después de la descolonización, Valladolid, 1988; id., El estado de necesidad y el uso de la fuerza en derecho internacional, Madrid, 1987; Iglesias Buigues, J., "La prohibición general del recurso a la fuerza y las resoluciones descolonizadoras de la Asamblea General de las Naciones Unidas", REDI, 1971, vol. XXIV, pp. 173 y ss.; Paniagua Redondo, R., "El uso de la fuerza armada: su regulación jurídica internacional", en varios autores, La regulación jurídica internacional de los conflictos armados, Barcelona, 1991; Pérez González, M., "Sobre la prohibición del recurso a la fuerza en las relaciones internacionales. Datos jurídico-políticos”, RFDUM, 1971, pp. 573 y ss.; Rodríguez Carrión, A., Uso de la fuerza por los Estados, Málaga, 1974.

9 Mariño Menéndez, F., "Zonas libres de armas nucleares", en varios autores, Cursos de derecho internacional de Vitoria Gasteiz, 1985, p. 155.

10 Expresión recogida oficialmente en la Conferencia Diplomática de Ginebra sobre la Reafirmación y el Desarrollo del Derecho Internacional Humanitario Aplicable en los Conflictos Armados, 1974-1977, Berna, 1978. Las Naciones Unidas utilizan la expresión sinónima de "derecho de los conflictos armados". 
rece centrado en la protección de la persona en caso de guerra, y en él se contienen una serie de disposiciones encaminadas a aliviar los sufrimientos y horrores propios de la guerra; es decir, el derecho internacional humanitario $^{11}$ viene referido a los límites a la violencia de la guerra establecidos mediante la regulación del comportamiento de las partes beligerantes durante el desarrollo de las hostilidades.

\section{La prohibición del uso de la fuerza}

Históricamente, el derecho internacional ha intentado limitar el uso de la fuerza mediante el establecimiento de los supuestos en que los Estados tenían un derecho a recurrir a la guerra (ius ad bellum) y de las modalidades que debían presidir la conducta de los Estados beligerantes en el desarrollo de las hostilidades (ius in bello). En el ámbito del derecho internacional clásico era admitido el ius ad bellum con carácter prácticamente ilimitado, ya que la guerra se configuraba como la última ratio en la protección de los intereses y derechos del Estado. ${ }^{12}$ La guerra se configuraba como medio de autoprotección.

En este contexto, debe traerse a colación el denominado "Derecho de La Haya", que está integrado por catorce convenciones, resultantes de las Conferencias de la Paz, celebradas en La Haya en 1899 y 1907. De acuerdo con los fines de la materia tratada, entre las mencionadas convenciones ${ }^{13}$ deben resaltarse el II, relativo a la limitación del empleo de la fuerza para el cobro de las deudas contractuales (Convención Drago-Porter), y el III,

11 Abellán Honrubia, V., "El derecho humanitario bélico: evolución histórica”, en varios autores, La regulación jurídica internacional de los conflictos armados, Barcelona, 1992; Calegeropoulos-Stratis, S., Droit humanitaire et droits de l'homme. La protection de la personne en période de conflit armé, Genèva, 1980; Castrén, E., Civil war, Helsinki, 1966; Mangas Martín, A., "La regulación jurídica internacional de los conflictos armados sin carácter internacional", en varios autores, $L a$ regulación jurídica internacional de los conflictos armados, Barcelona, 1992; Mangas Martín, A., Los conflictos armados internos y derecho internacional humanitario, Salamanca, 1990; varios autores, Las dimensiones internacionales del derecho humanitario, Madrid, 1990.

12 Rousseau, Ch., Le droit des conflits armés, París, 1983.

13 I. Arreglo pacífico de los conflictos internacionales; II. Limitación del empleo de la fuerza para el cobro de las deudas contractuales; III. Ruptura de hostilidades; IV. Leyes y costumbres de la guerra terrestre; V. Derechos y deberes de las potencias y personas neutrales en caso de guerra terrestre; VI. Régimen de los buques mercantes al empezar las hostilidades; VII. Transformación de buques mercantes en buques de guerra; VIII. Colocación de minas submarinas; IX. Bombardeo de fuerzas navales en tiempo de guerra; X. Aplicación a la guerra marítima de los principios del Convenio de Ginebra; XI. Restricciones al ejercicio del derecho de captura en la guerra marítima; XII. Establecimiento de un Tribunal Internacional de Presas; XIII. Derechos y deberes de las potencias neutrales en caso de guerra marítima; y XIV. Declaración acerca de la prohibición de arrojar proyectiles y explosivos desde los globos. 
sobre la ruptura de hostilidades, pues los mismos contienen incipientes limitaciones al uso de la fuerza. El artículo 1o. de la Convención II declaraba ilegal la guerra con la finalidad de cobrar deudas contractuales, salvo cuando el Estado deudor no aceptaba o no contestaba el ofrecimiento de arbitraje o, aceptándolo, imposibilitaba el establecimiento de un compromiso o, después del arbitraje, no cumplía la sentencia dictada al respecto. Por otra parte, la Convención III establecía la prohibición de recurrir a la guerra si previamente no concurría una declaración explícita y razonada de guerra o ultimátum, en tanto que forma condicional de declaración de guerra, si el otro Estado no aceptaba las condiciones en él dispuestas.

Entre 1913 y 1914, Estados Unidos de América concluyó una serie de tratados bilaterales, denominados Tratados Bryan, con diferentes Estados. En conformidad con los mismos, las partes se comprometían a solventar sus diferencias ante una comisión internacional de investigación y, en todo caso, no recurrirían a la guerra hasta que la comisión hubiera elaborado un informe sobre la disputa.

El Pacto de la Sociedad de Naciones de 1919, tras indicar en su Preámbulo que las partes declarasen "aceptar ciertas obligaciones de no recurrir a la guerra", disponía en su artículo 10 que los miembros de dicha organización:

Se comprometen a respetar y a mantener contra toda agresión exterior la integridad territorial y la independencia política presente de todos los miembros de la Sociedad. En caso de agresión, de amenaza o de peligro de agresión, el Consejo determinará los medios para asegurar el cumplimiento de esta obligación.

Seguidamente, el artículo 12.1 estipula que los miembros de la organización:

Convienen que si surge entre ellos algún desacuerdo capaz de ocasionar una ruptura, lo someterán al procedimiento de arbitraje o arreglo judicial, o al examen del Consejo. Convienen además, en que en ningún caso deberán recurrir a la guerra antes de que haya transcurrido un plazo de tres meses después de la sentencia de los árbitros o de la decisión judicial o del dictamen del Consejo.

Se trata, pues, de una renuncia parcial al uso de la guerra. Como puede advertirse, los instrumentos indicados se limitan a disponer una serie 
de limitaciones al uso de la fuerza en las relaciones internacionales y no es hasta la celebración en París, el 27 de agosto de 1928, del Pacto Briand-Kellogg (tratado general de renuncia a la guerra) cuando un tratado establece la prohibición jurídica de la guerra. En el artículo 1o. del citado tratado se disponía que las partes contratantes declaraban solemnemente que condenaban la guerra como medio de solución de las controversias internacionales y que renunciaban a ella como instrumento de política nacional en sus relaciones recíprocas. En consecuencia, se contemplaba el arreglo pacífico de las diferencias, por un lado, y la prohibición del recurso a la guerra para solventar las mismas, por otro.

Tras la Segunda Guerra Mundial, en el momento de elaborar la Carta de las Naciones Unidas, sus redactores incluyeron en el Preámbulo de la misma la resolución de "preservar a las generaciones venideras del flagelo de la guerra, que por dos veces durante nuestra vida ha infligido a la humanidad sufrimientos indecibles", y en conformidad con esta resolución, el artículo 2.4 de la carta ${ }^{14}$ dispone que:

Los miembros de la Organización, en sus relaciones internacionales, se abstendrán de recurrir a la amenaza o al uso de la fuerza contra la integridad territorial o la independencia política de cualquier Estado, o en cualquier otra forma incompatible con los propósitos de las Naciones Unidas.

Este principio fue confirmado y desarrollado mediante la adopción de la resolución 2625 (XXV), de 24 de octubre de 1970, relativa a la declaración sobre los principios de DIP referentes a las relaciones de amistad y a la cooperación entre los Estados de conformidad con la Carta de las $\mathrm{Na}$ ciones Unidas, que afirma el principio de que en las relaciones internacionales los Estados deben abstenerse de recurrir a la amenaza o al uso de la fuerza contra la integridad territorial o independencia política de cualquier Estado.

A la luz de la evolución operada en la materia, puede establecer un paralelismo entre la prohibición de la autotutela en los ordenamientos jurídicos internos y la prohibición del uso de la fuerza armada en las relaciones internacionales. En los ordenamientos internos, la autotutela sólo pudo ser proscrita a partir del momento en que se dispusieron una serie de acciones jurídicas que posibilitaron la justicia pública; esto es, la autode-

14 Goodrich, L. et al., Charter of the United Nations. Commentary and documents, Nueva York, 1969. 
fensa quedó desvirtuada a partir del momento en que los justiciables contaron con unos derechos que les permitían defender sus intereses ante instancias públicas. En la esfera del derecho internacional ocurrió otro tanto, ya que la limitación y posterior prohibición del recurso al uso de la fuerza han sido un proceso paralelo a la instauración de unos medios de arreglo pacífico de las controversias internacionales.

En virtud del artículo 2.4 de la carta, que proclama el principio de prohibición del uso de la fuerza, ${ }^{15}$ complementado por la definición de la agresión (resolución 3314 (XXIX), de 14 de diciembre de 1974, sobre definición de la agresión), cabe afirmar la prohibición de que un Estado utilice sus fuerzas armadas para invadir y ocupar el territorio de otro o atacar sus fuerzas armadas. Se trata, pues, de una disposición que declara la ilegalidad de la fuerza armada en las relaciones internacionales, ya que se configura como el prototipo de norma imperativa o de ius cogens. ${ }^{16} \mathrm{El}$ TIJ, en la sentencia relativa al Asunto del Estrecho de Corfú, rechazó la posibilidad de legitimar el recurso a la fuerza en el derecho internacional. ${ }^{17}$ Posteriormente, en la sentencia de 27 de junio de 1986, el mismo tribunal afirmó el principio de prohibición del uso de la fuerza como un principio de derecho internacional consuetudinario en función de la actitud de los Estados en relación con ciertos actos de la Asamblea General e instrumentos específicos como la declaración contenida en la resolución 2625 (XXV) y por las frecuentes manifestaciones de los representantes estatales sobre el citado principio, en el sentido de que lo mencionan a

15 El principio de prohibición del uso de la fuerza ha sido confirmado y desarrollado por varias resoluciones de las Naciones Unidas, tales como la resolución 1514 (XV), de 14 de diciembre de 1960, relativa a la "Declaración sobre la concesión de la independencia a los países y pueblos coloniales"; la resolución 2625 (XXV), de 24 de octubre de 1970, sobre la "Declaración relativa a los principios de derecho internacional referentes a las relaciones de amistad y a la cooperación entre los Estados de conformidad con la Carta de las Naciones Unidas"; la resolución 2131 (XX), del 21 de diciembre de 1965, relativa a la "Declaración sobre la inadmisibilidad de la intervención en los asuntos internos de los Estados y protección de su independencia y soberanía"; la resolución 2160 (XXI), de 30 de noviembre de 1966, sobre la "Estricta observación de la prohibición de recurrir a la amenaza o al empleo de la fuerza en las relaciones internacionales y el derecho de los pueblos a la autodeterminación", etcétera.

16 La naturaleza imperativa de esta disposición se manifiesta en el sentido de que es una norma que no admite acuerdo en contrario y que su violación es un atentado a los intereses esenciales de la comunidad internacional en su conjunto. En consecuencia, la prohibición de la amenaza o del uso de la fuerza deja de ser una regla convencional, solamente válida para los Estados que la acepten, para pasar a ser considerada una regla de DIP general que vincula y obliga a su cumplimiento a todos los Estados, por lo que el recurso a la guerra ya no es una competencia discrecional de los Estados soberanos al quedar prohibido.

17 CIJ, Recueil, 1949, pp. 4 y ss. 
menudo, no sólo como un principio de derecho internacional consuetudinario, sino incluso como un principio fundamental o esencial de ese derecho. ${ }^{18}$

En conformidad con la resolución 2625 (XXV), de 24 de octubre de 1970, todo Estado tiene el deber de abstenerse, en sus relaciones internacionales, de recurrir a la amenaza o al uso de la fuerza contra la integridad territorial o la independencia política de cualquier Estado, o en cualquier otra forma incompatible con los propósitos de las Naciones Unidas. Tal amenaza o uso de la fuerza constituye una violación del derecho internacional y de la Carta de las Naciones Unidas y no se empleará nunca como medio para resolver cuestiones internacionales. Además, según la citada resolución, ${ }^{19}$ por un lado, una guerra de agresión constituye un crimen contra la paz que, con arreglo al derecho internacional, entraña responsabilidad, y por otro, conforme a los propósitos y principios de las Naciones Unidas, los Estados tienen el deber de abstenerse de hacer propaganda en favor de las guerras de agresión.

El principio de "prohibición del uso de la fuerza" debe ser complementado con el concepto de agresión ${ }^{20}$ contenido en el anexo de la resolución 3314 (XXIX) de 14 de diciembre de 1974, que establece un régimen especial para el uso de la fuerza caracterizado por determinadas circunstancias agravantes. Como cuestión previa debe indicarse que el contexto en el cual debe situarse la definición de agresión contenida en la resolu-

18 CIJ, “Asunto...", cit., nota 7, pp. 99 y 100.

19 Según la comentada resolución, todo Estado tiene el deber de abstenerse de recurrir a la amenaza o al uso de la fuerza para: violar las fronteras internacionales existentes de otro Estado o como medio de resolver controversias internacionales, incluso las controversias territoriales y los problemas relativos a las fronteras de los Estados; violar las líneas internacionales de demarcación, tales como las líneas de armisticio que se establezcan por un acuerdo internacional del que sea parte o que esté obligado a respetar por otras razones, o de conformidad con ese acuerdo. Nada de lo anterior se interpretará en el sentido de que prejuzga las posiciones de las partes interesadas en relación con la condición y efectos de dichas líneas de acuerdo con sus regímenes especiales, ni en el sentido de que afecta a su carácter temporal. Asimismo, todo Estado tiene el deber de abstenerse de: recurrir a cualquier medida de fuerza que prive de su derecho a la libre determinación y a la libertad y a la independencia a los pueblos aludidos en la formulación del principio de la igualdad de derechos y de la libre determinación; organizar o fomentar la organización de fuerzas irregulares o de bandas armadas, incluidos los mercenarios, para hacer incursiones en el territorio de otro Estado; organizar, instigar, ayudar o participar en actos de guerra civil o en actos de terrorismo en otro Estado o de consentir actividades organizadas dentro de su territorio encaminadas a la comisión de dichos actos, cuando los actos a que se hace referencia en el presente párrafo impliquen el recurrir a la amenaza o al uso de la fuerza.

20 Rambaud, P., "La définition de l'agression par l'Organisation des Nations Unies", RGDIP, 1976, pp. 835 y ss.; Zourek, J., “Enfin une definition de l'agression”, AFDI, 1974, pp. 9 y ss. 
ción 3314 (XXIX) es el relativo al mantenimiento de la paz y seguridad internacionales, pues, en el preámbulo de la indicada resolución, las alusiones a tal fin son constantes. ${ }^{21}$ Una vez establecido el contexto en el que debe analizarse la agresión, ${ }^{22}$ el artículo 1o. la define como "el uso de la fuerza armada por un Estado contra la soberanía, la integridad territorial o la independencia de otro Estado o en cualquier otra forma incompatible con la Carta de las Naciones Unidas, tal como se enuncia en la presente definición". A partir de la definición general puede extraerse las siguientes notas características de la agresión: a) la noción conceptual de agresión viene limitada al uso de la fuerza armada; $b$ ) la noción de agresión se aplica única y exclusivamente a las relaciones entre Estados, y por consiguiente, el uso de la fuerza armada en el interior de un Estado no entra en el área de esta definición, y c) el texto glosado guarda silencio sobre la amenaza de la fuerza armada y tal circunstancia no permite considerar la referida amenaza como agresión.

En conformidad con la disposición segunda de su articulado:

El primer uso de la fuerza armada por un Estado en contravención de la carta constituirá prueba prima facie de un acto de agresión, aunque el Consejo de Seguridad puede concluir, de conformidad con la carta, que la determinación de que se ha cometido un acto de agresión no estaría justificada a la luz de otras circunstancias pertinentes, incluido el hecho de que los actos de que se trata o sus consecuencias no son de suficiente gravedad. ${ }^{23}$

21 "Basándose en el hecho de que uno de los propósitos fundamentales de las Naciones Unidas es mantener la paz y la seguridad internacionales y adoptar medidas eficaces para prevenir y eliminar amenazas a la paz y para suprimir actos de agresión y otros quebrantamientos de la paz", "recordando que el Consejo de Seguridad... hará recomendaciones o decidirá qué medidas serán tomadas... para mantener o restablecer la paz y la seguridad internacionales", etcétera.

22 La resolución comentada contiene una diversidad terminológica, ya que utiliza los términos “agresión” (artículos 10., 4o. y 5o.), "acto de agresión” (artículos 20. y 3o.), "uso de la fuerza armada" (artículos 10. y 2o.), "guerra de agresión" (artículo 5.2), etcétera.

23 Carrillo Salcedo, J., Curso de derecho internacional público, Madrid, 1994, p. 321. "En el artículo 2o. del anexo, se dispone que el primer uso de la fuerza armada por un Estado en contravención de la carta constituirá prueba prima facie de un acto de agresión, aunque el Consejo de Seguridad puede concluir, de conformidad con la Carta, que la determinación de que se ha cometido un acto de agresión no estaría justificada a la luz de otras circunstancias pertinentes, incluido el hecho de que los actos de que se trata o sus consecuencias no son de suficiente gravedad". Por su parte, Bermejo García apunta que el citado precepto establece el criterio de la anterioridad, salvo prueba en contrario, en orden a identificar al Estado agresor. Ahora bien, dado el poder discrecional del Consejo de Seguridad (artículos 2o. y 4o.), este criterio "sólo crea una presunción de culpabilidad que puede ser invertida por otras pruebas en contrario”. Bermejo García, R., El marco..., cit., nota 8, pp. 254 y 256 . 
Y, seguidamente el artículo 3o. dispone qué actos, entre otros, se caracterizarán como acto de agresión, ${ }^{24}$ complementando así la definición general de agresión. No obstante, tal enumeración es puramente indicativa, pues, a tenor del artículo 4o., la misma "no es exhaustiva y el Consejo de Seguridad podrá determinar qué otros actos constituyen agresión, con arreglo a las disposiciones de la carta".

Finalmente, cabe señalar que el artículo 5.1 dispone que "ninguna consideración, cualquiera que sea su índole... podrá servir de justificación de una agresión". Seguidamente, el apartado segundo de este mismo precepto establece que "la guerra de agresión es un crimen contra la paz internacional. La agresión origina responsabilidad internacional". Y, por último, el apartado tercero determina que "ninguna adquisición territorial o ventaja especial resultante de una agresión es lícita ni será reconocida como tal”. Según la resolución 2625 (XXV), de 24 de octubre de 1970, el territorio de un Estado no será objeto de ocupación militar derivada del uso de la fuerza en contravención de las disposiciones de la carta. El territorio de un Estado no será objeto de adquisición por otro Estado derivada de la amenaza o el uso de la fuerza. No se reconocerá como legal ninguna adquisición territorial derivada de la amenaza o el uso de la fuerza. Nada de lo dispuesto anteriormente se interpretará en un sentido que afecte: $a$ ) las disposiciones de la carta o cualquier acuerdo internacional anterior al régimen de la carta y que sea válido según el derecho internacional; o $b$ ) los poderes del Consejo de Seguridad de conformidad con la carta.

La agresión armada se presenta como la expresión más grave y caracterizada del empleo de la fuerza y, en palabras de AGO, sería considerada

24 Los actos contemplados por el artículo 3o. son los siguientes: $a$ ) la invasión o el ataque por las fuerzas armadas de un Estado, del territorio de otro Estado, o toda ocupación militar, aun temporal, que resulte de dicha invasión o ataque, o toda anexión, mediante el uso de la fuerza, del territorio de otro Estado, o de parte de él; $b$ ) el bombardeo, por fuerzas armadas de un Estado, del territorio de otro Estado, o el empleo de cualesquiera armas por un Estado contra el territorio de otro Estado; $c$ ) el bloqueo de los puertos o de las costas de un Estado por las fuerzas armadas de otro Estado; $d$ ) el ataque por las fuerzas armadas de un Estado contra las fuerzas armadas terrestres, navales o aéreas de otro Estado, o contra su flota mercante o aérea; $e$ ) la utilización de fuerzas armadas de un Estado, que se encuentran en el territorio de otro Estado con el acuerdo del Estado receptor, en violación de las condiciones establecidas en el acuerdo o toda prolongación de su presencia en dicho territorio después de terminado el acuerdo; $f$ ) la acción de un Estado que permite que su territorio, que ha puesto a disposición de otro Estado, sea utilizado por ese otro Estado para perpetrar un acto de agresión contra un tercer Estado; y $g$ ) el envío por un Estado, o en su nombre, de bandas armadas, grupos irregulares o mercenarios que lleven a cabo actos de fuerza armada contra otro Estado de tal gravedad que sean equiparables a los actos antes enunciados, o su sustancial participación en dichos actos. 
como "objeto de una prohibición de ius cogens", ${ }^{25}$ de la más típica e indiscutible prohibición de ius cogens tanto en el derecho internacional general como en el derecho del sistema de las Naciones Unidas. En este contexto existe una presunción de que el primer Estado en cometer alguno de los actos anteriormente indicados - invadir, ocupar, anexionar, atacar a las fuerzas armadas, etcétera - es responsable de la comisión de una acto de agresión, y por lo tanto la guerra de agresión es un crimen contra la paz internacional ${ }^{26}$ que origina responsabilidad internacional, y la adquisición territorial resultante de un acto de agresión será condenada ilícita. Por tanto, el incumplimiento de las obligaciones impuestas por la norma relativa a la prohibición del uso de la fuerza puede implicar la comisión de un crimen internacional, ya que dicha norma "constituye la norma básica y suprema del ordenamiento jurídico internacional, sobre la que se asienta el conjunto de las relaciones internacionales $\mathrm{y}$, asimismo, que esta norma representa el ejemplo más genuino de norma de naturaleza imperativa". ${ }^{27}$

En virtud de todo lo argumentado, como señala Carrillo Salcedo:

Resulta evidente que el proceso de cambio iniciado tras la Primera Guerra Mundial, concluido en 1945 con la adopción de la Carta de las Naciones Unidas, y consolidado posteriormente con la aprobación de las resoluciones 2625 (XXV) y 3314 (XXIX), ha dado lugar a la existencia de una norma de derecho internacional general, de carácter imperativo, que impone a todos los Estados el deber de abstenerse a recurrir a la amenaza o al uso de la fuerza armada. ${ }^{28}$

En consecuencia, la prohibición de la amenaza o del uso de la fuerza deja de ser una regla convencional, solamente válida para los Estados que la acepten, para pasar a ser considerada una regla de derecho internacional general ${ }^{29}$ que vincula y obliga a su cumplimiento a todos los Estados, por lo que el recurso a la guerra ya no es "una competencia discrecional de los Estados soberanos, al quedar prohibido y no simplemente limitado como había ocurrido en el Pacto de la Sociedad de Naciones". ${ }^{30}$

25 ACDI, vol. II, 1a. parte, 1980, pp. 56 y 57.

26 En este sentido, Remiro Brotóns, A., Derecho internacional público, Madrid, 1983, vol. 1, p. 182; y Paniagua Redondo, R., "El uso de la fuerza...”, cit., nota 8, p. 13.

27 Díaz Barrado, C., El consentimiento: causa de exclusión de la ilicitud del uso de la fuerza en derecho internacional, Zaragoza, 1989, p. 71.

28 Carrillo Salcedo, J., Curso..., cit., nota 23, p. 322.

29 CIJ, “Asunto...", cit., nota 7, pp. 99 y 100.

30 Carrillo Salcedo, J., El derecho internacional en perspectiva histórica, Madrid, 1991, pp. 82 y 83. 


\section{La reglamentación internacional de los conflictos armados}

El hecho de que la guerra haya sido proscrita, mediante la prohibición del uso de la fuerza como medio de solucionar los conflictos entre Estados, no implica que no existan en la actualidad enfrentamientos armados, pues, desde el fin de la Segunda Guerra Mundial los conflictos armados internacionales e internos y las denominadas guerras de liberación han sido un fenómeno constante. Por ello, junto al referido principio de prohibición del uso de la fuerza, no es de extrañar que el derecho internacional contenga una serie de disposiciones encargadas no sólo de regular la conducta a observar durante el desarrollo de enfrentamientos armados, sino también de proteger tanto a las posibles víctimas (heridos, enfermos, náufragos y población civil) como a los bienes de carácter civil, sin olvidar el medio ambiente, inmersos en un conflicto armado.

En la actualidad, el uso de la fuerza armada está prohibido en el ámbito de las relaciones internacionales, pero dicha prohibición no excluye la posibilidad de confrontaciones armadas y, por ello, una parte del derecho internacional público, denominado derecho internacional humanitario, aparece inspirado en el sentimiento de humanidad y centrado en la protección de la persona en caso de guerra, y en él se contienen una serie de disposiciones encaminadas a aliviar los sufrimientos y horrores propios de la guerra; es decir, el derecho internacional humanitario se refiere a los límites a la violencia de la guerra establecidos mediante la regulación del comportamiento de las partes beligerantes durante el desarrollo de las hostilidades. Así pues, este derecho se presenta como la respuesta a la necesidad de conciliar las exigencias militares con la humanidad indispensable en tiempo de guerra. Conciliación que debe realizarse sobre la base de los principios de proporcionalidad y racionalidad de los medios empleados, ya que la capacidad de los beligerantes para utilizar los mismos no es ilimitada, sino que viene delimitada por los principios enunciados.

El derecho internacional humanitario, en tanto que integrado por normas internacionales relativas a los conflictos armados y destinadas a proteger tanto a las víctimas de éstos como a los bienes culturales, se encuentra dividido entre el derecho de Ginebra, tendente a proteger y salvaguardar a las víctimas de los conflictos armados (tanto militares fuera de combate, como a las personas ajenas a las hostilidades), y el derecho de La Haya, determinante de los derechos y deberes de los beligeran- 
tes en la conducción de las operaciones militares. El derecho de Ginebra está integrado por los Convenios de Ginebra, de 12 de agosto de 1949, es decir, por el Convenio para mejorar la suerte de los heridos y enfermos de las fuerzas armadas en campaña; el Convenio para mejorar la suerte de los heridos y enfermos y náufragos de las fuerzas armadas en el mar; el Convenio relativo al trato de los prisioneros de guerra; y el Convenio relativo a la protección de personas civiles en tiempo de guerra. Estos convenios son complementados por los protocolos I y II adicionales a los Convenios de Ginebra, de 8 de junio de 1977, ${ }^{31}$ relativos a la protección de las víctimas de los conflictos armados internacionales y a la protección de las víctimas de los conflictos armados sin carácter internacional.

\section{El concepto de conflicto armado internacional}

La realidad internacional pone de manifiesto que en las relaciones entre los Estados surgen numerosas diferencias que en ocasiones si no alcanzan una solución pacífica, pueden llegar a una situación extrema que es la guerra. ${ }^{32}$ En este sentido, si bien existe la obligación de resolver las controversias por medios pacíficos, la guerra se presenta como un fenómeno que acontece con regular frecuencia en el seno de la sociedad internacional.

Desde un plano general, la guerra puede ser definida como la lucha armada entre sociedades humanas. Enfrentamiento organizado y no ocasional entre los ejércitos de dos o más Estados, siendo el elemento básico de la definición el uso de la fuerza — armada - por un Estado para imponer su voluntad a otro (s) Estado (s). En este contexto, el conflicto armado internacional puede ser definido como la "contienda entre dos o más Estados mediante sus fuerzas armadas, con objeto de vencer a la otra parte e imponerle aquellas condiciones de paz que estime el vencedor";33 así pues, estamos en presencia de una lucha violenta mediante el uso de la fuerza armada entre Estados.

31 Cassese, A., "The Geneva Protocols of 1977 on the humanitarian law of armed conflict and customary international law", Pacific Basin Law Journal, 1984, núms. 1-2, pp. 55 y ss.

32 Greenwood, C., "The concept of war in modern international law”, ICLQ, 1987, núm. 2, pp. 283 y ss.; Pilloud, C., "La noción de conflicto armado internacional: nuevas perspectivas", RICR, 1975, vol. 27, pp. 6 y ss.

33 Oppenheim, L., Tratado de derecho internacional público, Barcelona, 1966, t. II, vol. I, p. 208. 
A partir de la definición propuesta pueden extraerse las características que concurren en el seno de un conflicto armado internacional, a saber: $a$ ) la utilización del uso de la fuerza; $b$ ) entre Estados; $c$ ) mediante tropas pertenecientes a sus fuerzas armadas; y $d$ ) con el objeto de vencer a la otra parte en conflicto. En las páginas que siguen se hace una referencia somera a las características $b$ ), c) y $d$ ), pues la enunciada en primer lugar ya ha sido tratada en otra parte. En primer lugar, el conflicto armado debe darse entre Estados en tanto que sujetos miembros de la comunidad internacional; empero, también cabe englobar en su ámbito las llamadas guerras coloniales. En segundo lugar, el conflicto armado debe tener lugar mediante los miembros de las llamadas fuerzas armadas estatales, quedando excluidos de tal calificación los sujetos de carácter privado que no pertenezcan a las mismas (población civil).

Establecido el planteamiento general, se procede a tratar sobre las llamadas leyes de guerra o conjunto de normas que regulan las relaciones entre dos o más Estados que se encuentran en guerra en sentido técnicojurídico. Por ello, debe acudirse a los Convenios de La Haya y a los Convenios de Ginebra, para la determinación del concepto de conflicto armado internacional.

El derecho de La Haya entiende la guerra como una situación jurídica de carácter especial entre los Estados que integran la comunidad internacional. Así, desde un punto de vista formal, cabe definir la guerra -internacional- como "una relación entre uno o más gobiernos y, al menos, otro gobierno, en la que como mínimo uno de dichos gobiernos ya no permite que sus relaciones con el otro u otros se rijan por las leyes de la paz" $;{ }^{34}$ es decir, la guerra no viene identificada con el empleo de la fuerza armada, sino por la inaplicación de la normativa internacional propia del tiempo de paz, por un lado, y la aplicación de las disposiciones propias del derecho de guerra, por otro.

Con relación a la reglamentación señalada, los Convenios de Ginebra (1949) disponen la distinción entre "conflicto armado internacional" y "conflicto armado sin carácter internacional" o conflicto que surge "en el territorio de una de las Altas Partes contratantes" (artículo 3o. de los citados convenios). Por esto, debe establecerse tanto la noción de conflicto armado internacional como la de conflicto armado sin carácter internacional, y en este sentido, los criterios de distinción son los de legalidad, 
calidad y desigualdad de los sujetos enfrentados y la estabilidad en el estatuto jurídico de las partes en conflicto. ${ }^{35}$

En atención al criterio de legalidad, el derecho internacional prohíbe el uso de la fuerza en las relaciones internacionales entre Estados, afectando por tanto tal prohibición sólo al inicio de los posibles conflictos armados internacionales pero no a los conflictos armados internos; es decir, estos últimos no son ilegales con relación al derecho internacional. Según el criterio de la calidad y desigualdad de los sujetos enfrentados, el conflicto armado internacional tiene lugar entre dos o más Estados, mientras que el conflicto armado interno se desarrolla entre fuerzas armadas o grupos armados organizados de un mismo Estado entre sí (artículos 2o. y 30. de los Convenios de Ginebra, y artículo 1o. de los protocolos I y II). Por último, según el criterio de la estabilidad en el estatuto jurídico de las partes, existe una igualdad de las partes mientras dure el conflicto armado internacional en cuanto a su estatuto jurídico, pues siempre será aplicable el derecho de los conflictos armados, mientras que por el contrario, en el conflicto armado interno el estatuto jurídico de las partes es desigual y susceptible de cambio.

Según el artículo 2o., común a los Convenios de Ginebra, el concepto de conflicto armado internacional comprende los supuestos de "guerra declarada o de cualquier otro conflicto armado que surja entre dos o varias de las Altas Partes contratantes, aunque el Estado de guerra no haya sido reconocido por alguna de ellas" y "todos los casos de ocupación de la totalidad o parte del territorio de una Alta Parte contratante, aunque la ocupación no encuentre resistencia militar". En atención al texto del precepto transcrito, puede afirmarse que dicho artículo dispone una definición de los conflictos armados internacionales atendiendo al principio de la efectividad, pues no se exige una declaración de guerra ni un reconocimiento del denominado "estado de guerra" ${ }^{36}$ por las partes encontradas, sino única y exclusivamente la existencia de hostilidades efectivas. Asimismo, el artículo 1.4 del Protocolo I Adicional a los Convenios de Ginebra (1977) dispone que serán entendidos como conflictos armados inter-

35 Mangas Martín, A., "La regulación jurídica internacional de los conflictos armados sin carácter internacional", en varios autores, La regulación jurídica internacional de los conflictos armados, Barcelona, 1992; y varios autores, Los conflictos armados internos y derecho internacional humanitario, Salamanca, 1990, pp. 173 y ss.

36 Sorensen, M., Manual de derecho internacional público, México, 1973, p. 738. Según este autor, por "estado de guerra" cabe entender la ausencia de relaciones pacíficas entre dos o más Estados. 
nacionales "los conflictos armados en que los pueblos luchan contra la dominación colonial y la ocupación extranjera y contra los regímenes racistas, en el ejercicio del derecho de los pueblos a la libre determinación". ${ }^{37}$ En consecuencia, en el ámbito de las guerras internacionales debe comprenderse todas aquellas que se desarrollen entre Estados y en territorios coloniales.

El artículo 3o. de los Convenios de Ginebra contempla una noción amplia de conflicto armado interno y, en este sentido, cabe apreciar la presencia del mismo "cuando existe una parte contendiente que lleva a cabo una lucha armada colectiva y organizada dirigida contra el gobierno u otra parte contendiente". ${ }^{38}$ Así, según Mangas Martín, ${ }^{39}$ para la existencia de este tipo de conflicto armado es necesaria la concurrencia de una parte contendiente, lo que conlleva una organización, un propósito colectivo en la lucha armada y una capacidad de control sobre las acciones de los rebeldes por parte de un comandante responsable.

Por otra parte, el artículo 1.1 del Protocolo Adicional II dispone una noción estricta de conflicto armado interno; esto es, el citado protocolo se aplicará a los conflictos armados:

Que se desarrollen en el territorio de una Alta Parte contratante entre sus fuerzas armadas y fuerzas armadas disidentes o grupos armados organizados que, bajo la dirección de un mando responsable, ejerzan sobre una parte de dicho territorio un control tal que les permita realizar operaciones militares sostenidas y concertadas y aplicar el presente Protocolo.

En otras palabras, para que exista un conflicto armado interno es necesaria la concurrencia de las siguientes circunstancias: a) que se desarrollen en el territorio de una Alta Parte contratante; $b$ ) que se enfrenten las fuerzas armadas de la Alta Parte contratante contra fuerzas armadas disidentes o grupos armados organizados; $c$ ) que las fuerzas armadas disidentes o grupos armados organizados estén bajo la dirección de un mando responsable; $d$ ) que las fuerzas armadas disidentes o grupos armados organizados ejerzan control sobre una parte del territorio de la Alta Parte

37 Las denominadas guerras de liberación nacional aparecen incluidas en el Protocolo I adicional, de 8 de junio de 1977, referido a los conflictos armados internacionales y no en el Protocolo II adicional, de 8 de junio de 1977, referido a los conflictos armados sin carácter internacional.

38 Mangas Martín, A., "Derechos humanos y derecho humanitario bélico en el marco de los conflictos armados internos", cit., nota 11, p. 62.

39 Ibidem, p. 62. 
contratante; $e$ ) que se lleven a cabo operaciones militares sostenidas y concertadas; y $f$ ) que el control sobre las fuerzas armadas disidentes o grupos armados organizados les permita aplicar el Protocolo Adicional II.

En definitiva, el conflicto armado internacional puede ser definido como la contienda entre las fuerzas armadas de dos o más Estados, con objeto de vencer a la otra parte e imponerle las condiciones de paz que considere oportunas el vencedor; esto es, se trata de una lucha violenta mediante el uso de la fuerza armada entre Estados.

\section{EL ÁMBITO DE APLICACIÓN DE LA NORMATIVA}

La región de la guerra es "aquella parte de la superficie de la tierra en la cual los beligerantes pueden preparar y ejecutar las hostilidades entre sí", ${ }^{40}$ mientras que el teatro de la guerra son aquellas "porciones de tierra, mar o aire en o sobre las que tienen lugar efectivamente las hostilidades". ${ }^{41}$ Así pues, el teatro de la guerra comprende el territorio de los Estados beligerantes, entendiendo por tal el terrestre, el espacio aéreo suprayacente y la alta mar. Por regla general, las dos zonas - región y teatro de la guerra - coinciden, pero no siempre ocurre así, y según esta distinción ${ }^{42}$ se puede concluir afirmando que legalmente ningún lugar que no sea la región de la guerra puede ser teatro de la misma; empero como consecuencia del carácter total de las guerras modernas cabe observar que el teatro viene a comprender la totalidad de la región. Por otra parte, la determinación de la región de la guerra dependerá en todo momento de las partes en conflicto armado. Normalmente la región particular de cada guerra será la totalidad de los territorios (terrestres, marítimos y aéreos) de los países beligerantes. El territorio de los Estados neutrales o los territorios neutralizados están siempre fuera del teatro de la guerra, salvo que las tropas enemigas se asienten en los mismos y lleven a término operaciones en dichos territorios.

40 Oppenheim, L., Tratado..., cit., t. II, vol. I, nota 33, p. 243.

41 Ibidem, p. 245.

42 Tal distinción tiene su fundamento y razón de ser en el artículo 39 de las reglas de La Haya y del artículo 11 del Convenio V de La Haya. 


\section{LOS OBJETIVOS MILITARES}

Las necesidades militares deben conciliarse con las consideraciones de humanidad indispensables en tiempo de guerra y, en este sentido, la importante labor codificadora del denominado derecho de la guerra a comienzos del presente siglo fue la respuesta a tal necesidad conciliadora. Atendiendo a este planteamiento, las operaciones militares (hostilidades) deben ir dirigidas contra los llamados objetivos militares, quedando excluidas las hostilidades contra la población y los bienes de carácter civil. Dicho de otro modo, actualmente se encuentran limitadas de manera convencional las zonas donde se desarrollan las operaciones militares, en un intento de sustraer determinadas zonas espaciales u objetivos de los efectos destructivos de las hostilidades.

El derecho de la guerra clásico, que rigió desde finales del siglo pasado hasta comienzos del presente, impuso la concepción tradicional consistente en distinguir entre "ciudades abiertas" y "ciudades defendidas". Empero, esta distinción, no correspondía con la realidad, dada la evolución de los medios y técnicas de combate existentes durante 1914 y, especialmente, desde la Segunda Guerra Mundial. Por ello, frente a la concepción tradicional, cabe afirmar la concepción actual, que consiste en el establecimiento de zonas bajo protección especial.

\section{La noción de objetivo militar}

En el ámbito del derecho de la guerra, el término "objetivo" viene referido a las personas, bienes y localidades que pueden ser objeto de ataque durante un conflicto armado. Una vez efectuada esta afirmación, existe una generalizada distinción entre los "objetivos militares" y los "objetivos no militares", cuyo origen se encuentra en el principio de que la población y bienes civiles son un objetivo prohibido (artículo $52.1 \mathrm{del}$ Protocolo Adicional a los Convenios de Ginebra, de 12 de agosto de 1949, relativo a la protección de las víctimas de los conflictos armados internacionales). Así, la noción de "objetivo militar" responde a la necesidad de proteger a la población y bienes civiles y, en este sentido, el Protocolo I de 1977 Adicional a los Convenios de Ginebra, relativo a la protección de las víctimas de los conflictos armados internacionales, contiene una serie de disposiciones relativas a la protección de la población y bienes civiles. Por ello, las personas civiles son susceptibles de ser 
definidas como las "no pertenecientes a las fuerzas armadas" y sus bienes como "objetivos no militares".

En relación a la determinación de la noción de "objetivo militar", cabe distinguir entre la normativa contenida en el derecho de La Haya y el derecho de Ginebra: 1) Según el Reglamento de La Haya, ${ }^{43}$ por "objetivo militar" ${ }^{44}$ se entiende los lugares militarmente defendidos y afectados con un fin de carácter militar. 2) No obstante, como resultado de la evolución de los medios y métodos de combate, la definición resultante de los preceptos anteriormente reseñados queda anticuada y, por ello, el artículo 52.2 del Protocolo Adicional I de 1977 adopta una definición general, amplia y global ${ }^{45}$ al disponer que:

Los ataques se limitarán estrictamente a los objetivos militares. En lo que respecta a los bienes, los objetivos militares se limitarán a aquellos objetos que por su naturaleza, ubicación, finalidad o utilización contribuyan eficazmente a la acción militar o cuya destrucción total o parcial, captura o neutralización ofrezca en las circunstancias del caso una ventaja militar definida.

La definición transcrita viene determinada por la concurrencia de un triple elemento identificador:

a) La naturaleza, la ubicación, la finalidad y la utilización como elemento limitativo de los objetivos militares; tales criterios son limitativos de los objetivos militares y su razón de ser viene determinada por el hecho de que algunos objetivos militares tienen tal carácter per se (por ejemplo, instalaciones militares, fabricas de armamento, etcétera), mientras que otros carecen de tal carácter, pero en un momento dado, pueden

43 Artículo 25, relativo a lugares no defendidos ("el ataque o bombardeo por cualesquiera medios de ciudades, pueblos, viviendas o edificios que no estén defendidos está prohibido"), y 27, relativo a la protección de ciertos edificios siempre y cuando no se utilicen con fines militares.

44 En las reglas de la guerra aérea de La Haya de 1923 (artículo 24) se recogía de forma exhaustiva los objetivos militares; sin embargo, la lista de las categorías de objetivos militares que debía adjuntarse al Proyecto de reglas del CICR de 1956, nunca llegó a elaborarse. Sobre esta materia, Schindler, D. y Toman, J., The laws of armed conflicts. A collection of Conventions, Resolutions and other Documents, Ginebra, 1988, p. 253.

45 Institut de Droit International, Annuaire..., cit., p. 359 (sic). Según el criterio de la proporcionalidad, la resolución adoptada en su sesión de Edimburgo de 1969 señala que "pueden considerarse como objetivos militares aquellos que por su naturaleza, su finalidad o su utilización militar, contribuyen efectivamente a la acción militar o presentan un interés militar generalmente reconocido, de modo que su destrucción total o parcial proporciona, en las circunstancias en que se produzca, una ventaja militar sustancial, concreta e inmediata a quienes hayan procedido a destruirlos". El criterio adoptado por el artículo 52.2 del Protocolo I de 1977 es de carácter similar al contenido en el texto glosado de la resolución del Institut de Droit International. 
llegar a constituirse temporalmente en verdaderos objetivos militares (por ejemplo, la utilización de un hotel como cuartel general). Dicho en otras palabras, determinados objetivos no militares pueden llegar a serlo simplemente por razón de su ubicación o utilización.

b) Que las circunstancias anteriores contribuyan de forma eficaz a la acción militar; esto es, por el hecho de que un determinado objetivo sea militar no implica necesariamente que contribuya de forma eficaz a la acción militar. Por tanto, un objetivo militar debe contribuir de forma activa o eficiente en el contexto de las operaciones militares.

c) Que la destrucción, captura o neutralización del objetivo ofrezca una ventaja militar definida. Así pues, la destrucción total o parcial, captura o neutralización del objetivo militar vendrá condicionada por la existencia de una ventaja militar definida como resultado de tal acción y no por la obtención de unas simples ventajas militares. El hecho de que un objetivo revista el carácter de militar no implica necesariamente su destrucción, captura o neutralización por parte del enemigo, pues para que la misma sea legítima debe aportar una ventaja definida o clara y ello dependerá de la situación concreta de cada caso.

\section{Las zonas bajo protección especial}

A partir de la gran guerra, con la aparición de nuevos medios de combate, la población civil ya no es ajena a las operaciones militares, y especialmente la que se encuentra en ciudades no puede escapar a los efectos devastadores de éstas, por lo que su situación es altamente insegura. La situación descrita conlleva la necesaria limitación de las zonas de operación militares y, en este contexto, aparecen las denominadas zonas bajo protección especial o espacios protegidos contra los ataques, en tanto que dichas zonas se presentan como un medio suplementario para proteger a la población civil contra los bombardeos realizados por las fuerzas enemigas.

Los artículos 14 y 15 del Convenio de Ginebra relativo a la protección de personas civiles en tiempo de guerra, disponen la designación de dos tipos de zonas especiales, a saber: zonas y localidades sanitarias y de seguridad y zonas y localidades neutralizadas.

- Las zonas y localidades sanitarias y de seguridad "podrán” ser creadas o designadas por los Estados, es decir, los Estados no están obli- 
gados a pactar la creación de tales zonas, sino que se trata de una posibilidad que dependerá única y exclusivamente de su voluntad de decisión: la creación de dichas zonas corresponde con un acto facultativo estatal. La finalidad de estas zonas es la de proteger contra los efectos propios de la guerra a los heridos y enfermos, los inválidos, las personas de edad, los niños menores de quince años, las mujeres en cinta y a las madres de criaturas de menos de siete años. En cuanto al ámbito temporal, una vez que los Estados interesados han decidido crear una o varias zonas sanitarias y de seguridad, estas podrán ser designadas en dos momentos diferentes: en tiempo de paz y/o después de la ruptura de hostilidades (durante el desarrollo del conflicto armado).

- La creación de las zonas y localidades neutralizadas tiene su origen en una propuesta previa, directa o indirecta - a través de un Estado neutral o un organismo humanitario-, instada por una de las partes en conflicto y pendiente de aceptación por la otra. La finalidad perseguida con la creación de estas zonas es la de proteger frente a los peligros de los combates a los heridos y enfermos, combatientes o no, y personas civiles que no participen en las hostilidades, amén de no ejecutar ningún trabajo de carácter militar durante su estancia en dicha zona. Al contrario que en las zonas sanitarias y de seguridad, las zonas neutralizadas solamente podrán crearse después de la ruptura de hostilidades y su ámbito geográfico vendrá referido al territorio en donde tengan lugar los combates entre las partes. En todo caso, la existencia en el tiempo de la zona, así como su situación geográfica, administración, aprovisionamiento y control, dependerá de lo estipulado por las partes en el acuerdo de creación de la misma.

A estas zonas, contenidas en el Convenio de Ginebra sobre protección de personas civiles, el Protocolo I Adicional añadió dos nuevos tipos de zonas y localidades de protección especial: localidades no defendidas y la zona desmilitarizada.

- Las denominadas localidades no defendidas son lugares habitados que se encuentran próximos o en el interior de un territorio donde las fuerzas armadas estén en contacto y que están abiertos a la ocupación por la potencia enemiga. Los beligerantes no podrán atacar las localidades no defendidas según la prohibición expresa contenida en el Protocolo I Adicional de 1977. Según los apartados 2 y 4 del artículo 59, la designación de una localidad no defendida vendrá 
dada por una declaración unilateral. ${ }^{46}$ Asimismo, el estatuto de estas localidades es de carácter temporal, pues finaliza una vez que la ciudad es ocupada por la potencia adversaria.

- Las zonas desmilitarizadas resultan del acuerdo pactado entre las partes beligerantes, y basándose en éste, las operaciones militares no pueden extenderse a las mismas. A tenor de los apartados 1 y 2 del artículo 60, la creación de una zona desmilitarizada responde a la celebración de un acuerdo entre las partes contendientes. El estatuto de esta zona tendrá vigencia mientras la zona revista el carácter de desmilitarizada.

En ambos casos, tanto para las localidades no defendidas como para las zonas desmilitarizadas, deben concurrir las siguientes condiciones comunes: a) deberán haberse evacuado todos los combatientes, así como las armas y el material militar móviles; $b$ ) no se hará uso hostil de las instalaciones o establecimientos militares fijos; $c$ ) ni las autoridades ni la población cometerán actos de hostilidad; y $d$ ) no se emprenderá actividad alguna en apoyo de operaciones militares.

\section{Los bombardeos aéreos de ciudades}

En primer lugar cabe observar que la utilización de la denominada arma aérea contra objetivos militares está dentro de la legalidad. Una vez realizada dicha precisión preliminar, hay que preguntarse sobre la posible licitud o ilicitud del bombardeo aéreo de las ciudades, pues se plantea la dificultad relativa a la distinción de los objetivos militares de los que no revisten tal carácter y, en este sentido, hay que recordar los bombardeos indiscriminados realizados durante la guerra civil española y la Segunda Guerra Mundial.

Sin entrar en la evolución jurídica de la reglamentación de la guerra aérea, cabe observar que el artículo 51.4 del Protocolo I de Ginebra de 1977 dispone la prohibición de "los ataques indiscriminados", entendiendo por tales:

46 La designación de estas localidades tiene su origen en una declaración unilateral, realizada por una autoridad competente de una de las partes, dirigida a la otra parte en conflicto, quien acusará recibo de ella y, concurriendo efectivamente los requisitos indicados, tratará a la localidad designada como localidad no defendida; esto es, la designación de una localidad como localidad no defendida viene determinada por una manifestación de voluntad de una sola de las partes en conflicto. 
a) Los que no están dirigidos contra un objetivo militar concreto; $b$ ) los que emplean métodos o medios de combate que no pueden dirigirse contra un objetivo militar concreto; o $c$ ) los que emplean métodos o medios de combate cuyos efectos no sea posible limitar conforme a lo exigido en el presente protocolo; y que, en consecuencia, en cualesquiera de tales casos, pueden alcanzar indistintamente a objetivos militares y a personas civiles o a bienes de carácter civil.

\section{Asimismo, según el apartado 5:}

Se considerarán indiscriminados, entre otros, los siguientes tipos de ataque: a) los ataques por bombardeo, cualesquiera que sean los métodos o medios utilizados, que traten como objetivo militar único varios objetivos militares precisos y claramente separados situados en una ciudad, un pueblo, una aldea u otra zona en que haya concentración análoga de personas civiles o bienes de carácter civil; y b) los ataques, cuando sea de prever que causarán incidentalmente muertos y heridos entre la población civil, o daños a bienes de carácter civil, o ambas cosas, que serían excesivos en relación con la ventaja militar concreta y directa prevista.

La población civil está protegida por la prohibición referida a los ataques indiscriminados que condena el bombardeo de zona y la "alfombra de bombas", así como los ataques que podrían causar de forma incidental numerosas víctimas que, en todo caso, serían excesivas en relación con la ventaja militar concreta y directa prevista; esto es, en el último supuesto indicado cabe observarse (artículo 51.5.b) la existencia de la regla de proporcionalidad: un bombardeo dirigido contra un objetivo militar ocasionará daños accidentales a la población y bienes civiles, pero dichos daños serán ilícitos cuando sean excesivos con relación a la ventaja militar perseguida. El apartado 2 del precepto glosado dispone que "quedan prohibidos los actos de amenazas de violencia cuya finalidad principal sea aterrorizar a la población civil". A la vista de lo dispuesto por este precepto, los bombardeos que tengan por finalidad aterrorizar a la población civil conllevan una violación del derecho internacional.

\section{LOS MEDIOS Y MÉTODOS DE COMBATE}

El Protocolo I Adicional a los Convenios de Ginebra, de 12 agosto de 1949, relativo a la protección de las víctimas de los conflictos armados 
internacionales, dispone que "en todo conflicto armado, el derecho de las partes en conflicto a elegir los métodos o medios de hacer la guerra no es ilimitado" (artículo 35.1), ${ }^{47}$ prohibiendo "el empleo de armas, proyectiles, materias y métodos de hacer la guerra de tal índole que causen males superfluos o sufrimientos innecesarios" (artículo 35.2), ${ }^{48}$ por un lado, y "el empleo de métodos o medios de hacer la guerra que hayan sido concebidos para causar, o de los que quepa prever que causen daños extensos, duraderos y graves al medio ambiente natural", por otro.

Los medios de combate designan las armas susceptibles de ser utilizadas por las partes en caso de conflicto armado, mientras que, por el contrario, los métodos de combate corresponden con la utilización que esas mismas partes hagan de dichos medios durante el desarrollo del conflicto.

La limitación indicada — prohibición de utilizar determinados medios y métodos de combate — ${ }^{49}$ viene determinada por la necesidad de armonizar las posibles exigencias militares con las necesidades de carácter humanitario, y de esta forma, salvaguardar y proteger a las víctimas del conflicto armado. Así pues, entre los diversos medios y métodos de combate disponibles por una potencia para alcanzar un determinado objetivo militar, deberá utilizar aquellos que causen menos sufrimientos, daños o destrucción.

La fórmula contenida en el artículo 22 del Reglamento de La Haya relativa a que "los beligerantes no tienen un derecho ilimitado en cuanto a la elección de medios para dañar al enemigo", aparece nuevamente recogida, si bien es cierto que con alguna variante, en el artículo $35.1 \mathrm{del}$ Protocolo I de 1977, al disponer que "el derecho de las Partes en conflicto a elegir los métodos o medios de hacer la guerra no es ilimitado". A la norma fundamental proclamada en el apartado primero, el apartado segundo prohíbe el empleo de medios y métodos de combate "de tal índole que causen males superfluos o sufrimientos innecesarios". La prohibición contenida en el artículo 35.2 se está refiriendo a medios y métodos de combate que puedan causar perjuicios o dolores inútiles o padecimientos no necesarios.

47 Según el artículo 22 del Reglamento de La Haya, "los beligerantes no tienen un derecho ilimitado en cuanto a la elección de medios para dañar al enemigo".

48 El artículo 23 del Reglamento de La Haya prohíbe el empleo de veneno y de aquellas armas, proyectiles y material que causen daño innecesario.

49 Bretton, Ph., "Le problème des méthodes et moyens de guerre ou de combat dans les Protocoles aditionnels aux Conventions de Gèneve du 12 aout de 1949”, en RGDIP, 1978, pp. 32 y ss. Cassese, A., "Weapons causing unnecessary suffering are they prohibited?", en RIV, 1975, pp. 12 y ss. 


\section{LA PROTECCIÓN DE LAS VÍCTIMAS DE LOS CONFLICTOS ARMADOS}

El derecho internacional humanitario se articula en torno al principio de que la fuerza - armada - solamente puede dirigirse contra personas que, a su vez, hagan uso de la misma. Atendiendo a este principio, cabe señalar que la conducción de las hostilidades está reservada para los denominados combatientes o beligerantes, ya que según la normativa internacional solamente éstos están cualificados para realizar o cometer actos hostiles, por un lado, y para ser objeto de ataques por parte del enemigo, por otro. Según la citada normativa, tendrán derecho a ser tratados como prisioneros de guerra en caso de ser capturados por las fuerzas enemigas.

$\mathrm{Al}$ estar reservada la conducción de las hostilidades a los combatientes, los no combatientes deberán abstenerse de realizar actos hostiles y, en contrapartida, no podrán ser objetos de ataques armados. Así, la categoría de personas no combatientes vendrá integrada por la población civil, siempre que no tomen las armas y que no participen o colaboren activamente en el uso de la fuerza contra el adversario, el personal sanitario y capellanes, aunque pertenezcan a las fuerzas armadas. La finalidad de la distinción propuesta radica en la necesidad de que los denominados no combatientes no sufran, dentro de lo posible, los efectos de las operaciones militares ejecutadas durante el transcurso de los conflictos armados.

La utilización de la fuerza armada deberá realizarse, en el marco de las limitaciones y prohibiciones dispuestas por el derecho internacional humanitario, ${ }^{50}$ en defensa de los no combatientes, y en virtud de este planteamiento, la máxima a seguir durante el desarrollo de los conflictos armados es que solamente los combatientes podrán ser objeto de ataques, mientras que, por el contrario, los denominados no combatientes no podrán ser objeto de los mismos, dada la salvaguardia que el derecho internacional humanitario dispone en su favor; consecuentemente los beligerantes deben distinguir entre personas y bienes civiles, por una parte, y combatientes y objetivos militares, por otra, dirigiéndose las operaciones militares única y exclusivamente contra estos últimos. 


\section{Los combatientes}

El término combatiente ha sido utilizado con carácter general para denominar a todos los miembros integrantes de las fuerzas armadas, excepto los pertenecientes al personal sanitario y religioso (capellanes), y a cualquier persona civil que, en un momento dado, tome las armas.

El artículo 1o. del Reglamento de La Haya de 1907 dispone la siguiente caracterización de los beligerantes, a saber:

Las leyes, los derechos y los deberes de la guerra no se aplican solamente al ejército, sino también a las milicias y a los cuerpos de voluntarios que reúnan las condiciones siguientes: 1 . Tener a su frente una persona responsable de sus subordinados. 2. Poseer algún signo distintivo fijo y perceptible a distancia. 3. Llevar armas abiertamente. 4. Sujetarse, en sus operaciones, a las leyes y costumbres de la guerra.

La caracterización de beligerante, dispuesta por el precepto contemplado, permite englobar bajo la misma no sólo a los ejércitos regulares, sino también a las milicias y a los cuerpos de voluntarios, siempre y cuando reúnan las condiciones exigidas en el referido precepto.

Seguidamente, el artículo 3o. del citado cuerpo convencional dispone que "las fuerzas armadas de las partes beligerantes pueden componerse de combatientes y de no combatientes. En caso de captura por el enemigo, unos y otros tienen derecho al trato de prisioneros de guerra". Como puede observarse, a pesar de referirse a los combatientes y no combatientes, el precepto glosado no contiene distinción alguna entre ambas figuras, simplemente se limita a disponer que las fuerzas armadas pueden estar compuestas por combatientes y no combatientes. Por tanto, definir lo que es un beligerante determina si una persona portadora de armas debe ser tratada como prisionero de guerra; en todo caso, al igual que los combatientes, los no combatientes mencionados en el artículo 3o. de la Reglamentación de La Haya que sean capturados deben ser tratados también como prisioneros de guerra.

En el contexto descrito, a la vista del apartado A del artículo 4o. del Convenio de Ginebra relativo al trato debido a los prisioneros de guerra, puede apreciarse una serie de circunstancias que deben tomarse en cuenta a la hora de examinar el tema relativo a los combatientes: 1) Cabe observar que los cuatro criterios previstos en el artículo 1o. del Reglamento de La Haya se han convertido en unos meros criterios que dan derecho al 
trato de los prisioneros de guerra. 2) El citado artículo recoge en su apartado segundo una serie de modalidades armadas desarrolladas durante el transcurso de la Segunda Guerra Mundial, especialmente sobresale la referencia a los movimientos de resistencia organizados. 3) El precepto incluye una innovación referida a los miembros de fuerzas armadas regulares pertenecientes a un gobierno o autoridad no reconocida por la potencia en cuyo poder hubieran caído; esto es, los citados miembros formarán parte de las fuerzas armadas y, por tanto, deberá dispensárseles el trato de prisionero de guerra.

Los combatientes son miembros de las fuerzas armadas, pero no todos los miembros de dichas fuerzas son combatientes, ya que el personal sanitario y religioso, a pesar de detentar tal condición, no son combatientes. Así, son combatientes aquellos miembros de las fuerzas armadas que "tienen derecho a participar directamente en las hostilidades" (artículo 43.2) y además puedan "distinguirse de la población civil en el curso de un ataque o de una operación militar preparatoria de un ataque" (artículo 44.3). Empero, en relación con esta última condición, el precepto 44.3 añade que:

Sin embargo, dado que en los conflictos armados hay situaciones en las que, debido a la índole de las hostilidades, un combatiente armado no puede distinguirse de la población civil, dicho combatiente conservará su estatuto de tal siempre que, en esas circunstancias, lleve sus armas abiertamente: $a$ ) durante todo el enfrentamiento militar; y $b$ ) durante el tiempo en que sea visible para el enemigo mientras está tomando parte en un despliegue militar previo al lanzamiento de un ataque en el que va a participar.

En consecuencia, son combatientes tanto los "miembros de las fuerzas armadas de una parte en conflicto" como los guerrilleros, pero se hace necesario determinar qué debe entenderse por tales fuerzas y, en este sentido, el artículo 43.1 del citado protocolo dispone que las fuerzas armadas de una parte en conflicto se componen de todas las fuerzas, grupos y unidades armados y organizados, colocados bajo un mando responsable de la conducta de sus subordinados ante esa parte, aun cuando esta última esté presentada por un gobierno o por una autoridad no reconocidos por una parte adversa. Las fuerzas armadas deberán estar sometidas a un régimen de disciplina interna que haga cumplir, inter alia, las normas de derecho internacional aplicables en los conflictos armados. 
La disposición comentada contiene una definición amplia de las fuerzas armadas, en la que la fórmula "todas las fuerzas, grupos y unidades armados y organizados" sustituye los términos "fuerzas armadas, otras milicias y otros cuerpos voluntarios, incluidos los de movimientos de resistencia organizados", contenidos en el artículo 4o. del Convenio de Ginebra relativo al trato a los prisioneros de guerra, abandonando las exigencias del citado convenio de 1949, excepto la que viene referida a "tener a su frente una persona responsable de sus subordinados" que adopta la forma modificada de "bajo un mando responsable de la conducta de sus subordinados ante esta parte" (en relación a las fuerzas, grupos y unidades).

\section{A. Los prisioneros de guerra}

En un principio, remontándonos a la Antigüedad, los combatientes que caían en poder del enemigo eran por regla general exterminados. Ahora bien, tal práctica fue variando y evolucionando con el transcurso del tiempo hasta que, finalmente, en 1899 se aprobó el Reglamento de La Haya (revisado en 1907), cuyo capítulo II (artículos 4o. a 20) estaba dedicado a los prisioneros de guerra. A esta primera reglamentación internacional en la materia siguió el Convenio de Ginebra de 1929 y, posteriormente, el Convenio de Ginebra, de 12 de agosto de 1949, relativo al trato de los prisioneros de guerra, completado por los artículos 43 y 44 del Protocolo Adicional de 1977. El citado convenio se presenta como la "carta", "estatuto" o "código de los prisioneros de guerra", siendo una salvaguardia esencial para millones de personas en las duras y penosas condiciones del cautiverio, ya que dicho convenio dispone los principios fundamentales relativos a la protección a que tienen derecho los combatientes que caen en poder de las fuerzas enemigas.

En conformidad con el artículo 4o., letra a, del Convenio de Ginebra de 1949, son prisioneros de guerra: ${ }^{51}$

Las personas que, perteneciendo a alguna de las siguientes categorías, caigan en poder del enemigo:

1) Miembros de las fuerzas armadas de una Parte contendiente, así como miembros de milicias y cuerpos de voluntarios que formen parte de esas fuerzas armadas. 
2) Miembros de otras milicias y miembros de otros cuerpos voluntarios, incluso los de movimientos de resistencia organizados, pertenecientes a una parte contendiente y que actúen fuera o dentro de su propio territorio, aunque este territorio se halle ocupado, siempre que esas milicias o cuerpos organizados, incluso los movimientos de resistencia organizados, cumplan las condiciones siguientes: $a$ ) que figure a su cabeza una persona responsable por sus subordinados; $b$ ) que lleven un signo distintivo fijo y fácil de reconocer a distancia; $c$ ) que lleven francamente las armas; $d$ ) que se conformen, en sus operaciones, a las leyes y costumbres de la guerra.

3) Miembros de las fuerzas armadas regulares pertenecientes a un gobierno o a una autoridad no reconocidos por la potencia en cuyo poder hayan caído.

4) Personas que sigan a las fuerzas armadas sin formar parte integrante de ellas, tales como miembros civiles de tripulaciones de aviones militares, corresponsales de guerra, proveedores, individuos de unidades de trabajo o de servicios encargados del bienestar de las fuerzas armadas, a condición de que para ello hayan recibido permiso de las fuerzas armadas que acompañan, teniendo éstas la obligación de entregarles a tal efecto una tarjeta de identidad semejante al modelo adjunto.

5) Miembros de las tripulaciones, incluso capitanes, pilotos y grumetes, de la marina mercante, y tripulaciones de la aviación civil de las partes contendientes, que no gocen de trato más favorable en virtud de otras disposiciones del derecho internacional.

6) La población de un territorio no ocupado que, al acercarse el enemigo, tome espontáneamente las armas para combatir a las tropas invasoras, sin haber tenido tiempo para constituirse en fuerzas armadas regulares, siempre que lleve francamente las armas y respete las leyes y costumbres de la guerra.

Sin embargo, la gran novedad del artículo comentado aparece contemplada en su letra B al disponer que:

Se beneficiarán igualmente del trato reservado por el presente convenio a los prisioneros de guerra: 1) Las personas que pertenezcan o hayan pertenecido a las fuerzas armadas del país ocupado sí, por razón de esta pertenencia, la Potencia ocupante, aunque las haya inicialmente liberado mientras las hostilidades se efectuaban fuera del territorio que ocupe, considera necesario proceder a su internamiento, especialmente después de una tentativa fracasada de dichas personas, para incorporarse a las fuerzas armadas a que pertenezcan, y que se hallen comprendidas en el combate, o cuando hagan caso omiso de la orden que se les dé para su internamiento. 2) Las 
personas que pertenezcan a una de las categorías enumeradas en el presente artículo, que hayan sido recibidas en sus territorios por Potencias neutrales o no beligerantes, y a quienes éstas tengan la obligación de internar en virtud del Derecho internacional, bajo reserva de cualquier trato más favorable que dichas Potencias juzgasen oportuno concederles, excepción hecha de las disposiciones de los artículos 8o., 10, 15, 30.5, 58 a 68 inclusives, 92, 126, y cuando entre las Partes contendientes y la Potencia neutral o no beligerante interesada existan relaciones diplomáticas, de las disposiciones concernientes a la Potencia protectora. Cuando existan tales relaciones diplomáticas, las Partes contendientes de quienes dependan dichas personas estarán autorizadas para ejercer, respecto a ellas, las funciones que el presente convenio señala a las Potencias, sin perjuicio de las que dichas Partes ejerzan normalmente a tenor de los usos y de tratados diplomáticos y consulares.

El apartado transcrito dispone la protección en favor de dos categorías concretas de personas: las personas que la potencia ocupante decide internar como consecuencia de pertenecer o haber pertenecido a las fuerzas armadas del Estado ocupado, y las personas que, debiendo tener la consideración de prisionero de guerra, y habiendo sido recibidas por Estados neutrales o no beligerantes, deban ser internadas en virtud de las disposiciones del derecho internacional. Como puede observarse, el precepto glosado trata de establecer el concepto de prisionero de guerra mediante un sistema puramente numerativo, esto es, enumera diferentes categorías de personas que una vez capturadas por el enemigo deben ser tratadas como prisioneros de guerra. No obstante, por regla general, puede ser calificado como prisionero de guerra todo combatiente que caiga en poder del enemigo.

\section{B. La condición jurídica y protección general de los prisioneros de guerra}

Los prisioneros de guerra se encuentran en poder de la potencia que los ha capturado, siendo ésta la responsable última del trato que se dispense a dichos prisioneros, independientemente de cualquier responsabilidad individual.

La protección general de los prisioneros de guerra gira en torno a la no consideración del prisionero como responsable de la guerra; esto es, al combatiente capturado no se le puede imputar ni la guerra en sí misma ni su desarrollo, ya que el cautiverio tiene por único objeto el evitar que el 
combatiente pueda participar nuevamente en las hostilidades. En consecuencia, el cautiverio no reviste un carácter punitivo ni infamante, sino que debe ser entendido como una medida de precaución.

El estatus de prisionero conlleva que sean tratados humanamente y en todo momento se respete su persona física y moral (artículo 13 del convenio). El derecho al respeto a la persona física de los prisioneros implica: a) que no se cometan actos ilícitos que pongan en grave peligro su salud (artículo 38 del convenio); b) que no sean objeto de vejación (artículo 38 del convenio); c) que no se les prive de servicios de higiene y de actividades físicas, recreativas e intelectuales (artículo 38 del convenio); $d$ ) que las condiciones de alimentación, alojamiento y vestimenta sean suficientes (artículos 15, 25, 26 y 27 del convenio); e) que no sean situados en zonas peligrosas y de combate (artículo 19 del convenio); y $f$ ) que no se les despoje de sus bienes o efectos de uso personal (artículo 18 del convenio).

Por otra parte, no se debe vulnerar el derecho al honor de los prisioneros, esto es, $a$ ) no pueden ser objeto de tratos humillantes, degradantes, insultos, etcétera; $b$ ) debe facilitárseles personal religioso y médico (artículo 33 del convenio), así como la práctica de los deberes religiosos (artículo 34 del convenio); y c) se les debe entregar un salario (artículo $60 \mathrm{del}$ convenio).

A las circunstancias indicadas cabe añadir que debe permitirse a los prisioneros: a) recibir correspondencia (artículo 71 del convenio) y envíos - ropa, alimentos, etcétera-; así como enviar correspondencia al exterior); $b$ ) elegir un representante de su nacionalidad encargado de representarlos ante las autoridades (artículo 79 del convenio); y c) presentar posibles quejas o solicitudes ante las autoridades (artículo 78 del convenio). Asimismo, las autoridades: $a$ ) deben permitir a los prisioneros en cautiverio enviar a su familia y a la Agencia Central de Informaciones (artículo 123 del convenio) sobre los Prisioneros, con sede en Ginebra, la denominada tarjeta de captura (artículo 70 del convenio), informando de su captura, estado de salud y dirección postal; $b$ ) deben instalar una oficina oficial de información sobre los prisioneros de guerra en su poder y sobre los combatientes fallecidos (artículo 122 del convenio); y c) deben devolver los objetos personales y de valor de los prisioneros fallecidos (artículo 122 del convenio). 


\section{La población civil}

Una vez contemplado el término "combatiente", es necesario definir tanto las personas civiles como la población civil ${ }^{52} \mathrm{y}$, para ello, hay que remitirse al articulado comprendido en el Convenio de Ginebra, de 12 de agosto de 1949, sobre la protección de las personas civiles en tiempo de guerra y al Protocolo I Adicional de 1977.

El artículo 4o. del Convenio de Ginebra dispone que "quedan protegidas por el convenio las personas que en un momento cualquiera y de cualquier manera que sea se encontraren, en caso de conflicto u ocupación, en poder de una Parte contendiente o de una Potencia ocupante de la cual no sean súbditas". Por otra parte, el artículo 13 del mismo cuerpo convencional declara que "las disposiciones del presente título se refieren al conjunto de las poblaciones de los países contendientes sin distingo alguno desfavorable, especialmente en cuanto a la raza, la nacionalidad, la religión o la opinión política y tienen por objetivo aliviar los sufrimientos engendrados por la guerra".

Contemplados los preceptos transcritos, por persona civil debe entenderse a toda persona que no es miembro de un ejército y que no pertenece a las milicias ni a los cuerpos voluntarios, incluidos los movimientos de resistencia organizados, sean o no reconocidos por la parte adversa. En definitiva, las personas civiles son aquellas que no participan en las hostilidades y, en consecuencia, son los beneficiarios de la protección dispensada por el derecho internacional humanitario, sea o no internacional el conflicto y sea cual fuere el territorio en que se encuentren, tanto si la guerra ha sido declarada expresamente como si no, y ésta haya sido o no reconocida una parte en conflicto por el adversario.

\section{A. La protección de la población civil}

La regla fundamental a partir de la cual se articula la protección general de la población civil aparece recogida en el artículo 27 del Convenio de Ginebra de 1949, relativo a la protección de las personas civiles en tiempo de guerra, al proclamar el respeto a la persona humana, a su honor, a sus derechos familiares, a sus convicciones y prácticas religiosas. El citado convenio dispone dos regímenes diferenciados de protección: uno referido "al conjunto de las poblaciones de los países contendientes" 
(artículo 13 del convenio). La protección de estas personas aparece contemplada en el título II del convenio IV: "Protección general de las poblaciones contra ciertos efectos de la guerra", y otro que incluye a "las personas que en un momento cualquiera y de cualquier manera que sea se encontraren, en caso de conflicto u ocupación, en poder de una parte contendiente o de una potencia ocupante de la cual no sean súbditos" (artículo 4o. del convenio), quedando expresamente excluidas las personas objeto de protección por parte de los restantes tres convenios, así como los súbditos de un Estado que no sea parte del convenio.

En el contexto descrito, el referido convenio se configura como el primer instrumento convencional que contempla con carácter general la materia,${ }^{53}$ aunque si bien es amplio y concreto en la protección de los individuos frente a los peligros de la guerra, no ocurre lo mismo en la esfera de la protección del conjunto de la población; es decir, el ámbito protector del convenio se centra sobre las personas civiles cuando se hallen en territorio enemigo y cuando se encuentren en territorio ocupado por las fuerzas de la potencia enemiga. Sin embargo, a pesar del progreso considerable que significó este instrumento convencional, en él no aparecían protegidas las personas civiles frente a los efectos de las armas, a pesar de constituir un número muy elevado de víctimas durante los conflictos armados. Ante la situación descrita se hizo necesario afrontar el tema, y fruto de la Conferencia de Ginebra sobre la reafirmación y desarrollo del derecho internacional humanitario fue la adopción de los protocolos adicionales a las Convenciones de Ginebra de 1949.

El Protocolo Adicional I de 1977, relativo a la protección de las víctimas de los conflictos armados internacionales, implica una ampliación de la esfera protectora de la población civil entendida en su conjunto en cuanto tal, prohibiendo que tanto dicha población como sus bienes sean objeto de ataques. Por tanto, el principio básico que rige el espíritu del protocolo es que en todo momento debe distinguirse entre la población civil

53 Los artículos 46 y 50 de la Convención de La Haya de 1907 contienen unas disposiciones de carácter muy general en materia de respeto a la vida y libertad de los habitantes del territorio ocupado. Así, el artículo citado en segundo lugar dispone de forma expresa que no puede ser aplicada ninguna pena general, pecuniaria o de cualquier otro tipo, a la población civil por actos de los individuos de los que no pueda considerarse como responsable colectivamente. Esta situación vino a ser modificada por la Convención de Ginebra sobre la protección de la población civil en tiempo de guerra, ya que en ella se dispone una limitación de las competencias de la potencia ocupante, así como la adopción de medidas especiales de protección para determinadas personas y la creación de zonas sanitarias y de seguridad. 
y los combatientes, por lo que los ataques se han de dirigir solamente contra los objetivos militares (artículo 50. 1 y 2 del Protocolo Adicional I).

\section{B. La interacción entre los derechos humanos y el derecho internacional humanitario}

En virtud de la interacción entre los derechos humanos y el derecho internacional humanitario y del consenso en el seno de la comunidad internacional en el sentido de que los derechos humanos fundamentales deben ser respetados tanto en tiempo de paz como en tiempo de guerra, ${ }^{54} \mathrm{se}$ indican seguidamente las disposiciones internacionales en la materia, de aucerdo con su aplicación en los casos de conflicto armado internacional.

- La prohibición de ejecuciones sumarias y arbitrarias (artículo 3o. de la Declaración Universal de los Derechos Humanos y del artículo 6o. del Pacto Internacional de Derechos Civiles y Políticos).

- La prohibición de torturas y tratos inhumanos (artículos 27, 31 y 32 del Convenio de Ginebra de 1949 sobre la Protección de Personas Civiles en Tiempo de Guerra).

- Prohibición de detenciones, prisión y deportaciones arbitrarias (artículos 41, 42, 43, 48, 68 y 78 del Convenio de Ginebra sobre Trato relativo a la Protección de las Personas Civiles en Tiempo de Guerra, y artículo 9o. de la Declaración Universal de los Derechos del Hombre).

- El derecho a salir libremente del país (artículo 35 del Convenio de Ginebra y artículo 12.2 del Pacto Internacional de Derechos Civiles y Políticos).

- La libertad religiosa, de expresión y de reunión (artículos 18, 19 y 21 del Pacto Internacional de Derechos Civiles y Políticos).

- La protección especial de mujeres y niños (artículos 14, 27, 68 y 76 del convenio, y artículo 24 del Pacto Internacional de Derechos Civiles y Políticos).

54 Mangas Martín, A., "Derechos humanos...”, cit., nota 11, p. 63. Puntualiza esta autora que: "aunque estas cláusulas de suspensión de derechos y garantías de los Convenios sobre derechos humanos puedan permitir al Estado parte restringir los derechos protegidos en tales convenios de derechos humanos en caso de conflicto armado interno, tal suspensión no tendrá efecto cuando el Estado esté obligado a respetar esos u otros derechos y garantías de la persona en virtud de otras normas internacionales específicas: cláusula Martens, artículo 3o. común a los Convenios de Ginebra, Protocolo adicional II". 
- El derecho a la salud (artículos 56 y 57 del Convenio de Ginebra).

- El derecho a la educación (artículos 13.1, 15 y 50 del Convenio de Ginebra).

\section{LA PROTECCIÓN DE LOS BIENES CULTURALES}

La protección de los bienes culturales en caso de conflicto armado ${ }^{55}$ debe enmarcarse en el ámbito de la moderna concepción sobre establecimiento de zonas bajo protección especial; esto es, la protección de dichos bienes es una de las posibles medidas susceptibles de ser adoptadas para limitar convencionalmente las zonas de las operaciones militares.

La medida relativa a la protección de los bienes culturales en caso de guerra es relativamente reciente y responde a la idea de que los bienes culturales son, en tanto que base de la civilización humana, patrimonio común de la humanidad. ${ }^{56}$ Por ello, no es extraño que en el siglo XIX, al iniciarse la codificación de las leyes de la guerra, se pensara en la suerte de las obras de arte (por ejemplo, monumentos históricos, descubrimientos arqueológicos, archivos, bibliotecas, etcétera) en tiempo de guerra.

\section{La protección jurídico-internacional de los bienes culturales}

En el ámbito de la protección jurídico-internacional de los bienes culturales, cabe distinguir dos momentos cuya frontera diferenciadora en el tiempo debe establecerse en 1954. Con anterioridad al citado año solamente existían disposiciones aisladas u ocasionales sobre la referida materia. Así, en los convenios realizados en La Haya en 1899 y 1907 solamente se contienen unas disposiciones que de forma ocasional vienen referidas a la protección de los bienes culturales.

El reglamento anexo al IV Convenio de 1907, sobre las leyes y costumbres de la guerra terrestre, contiene algunas normas que, por una parte, contribuyen a la protección de los bienes culturales indirectamente y, por otra, designan de manera expresa dicha protección. Entre las primeras, de carácter indirecto, que versan sobre la protección de los bienes ci-

55 Verri, P., "La suerte de los bienes culturales en los conflictos armados", RICR, 1985, núm. 68 , pp. 67 y ss.

56 Visscher, Ch. de, "La protection internationale des objets d'art et des monuments historiques", RDILC, 1935. 
viles en general, y por extensión protegen los bienes culturales, cabe citar las siguientes: 1) Prohibición de destruir o apoderarse de las propiedades enemigas. 2) Prohibición de bombardear, por cualquier medio que sea, ciudades, pueblos, casas o edificios que no estén defendidos. 3) Prohibición de entregar al pillaje una población o localidad, aunque sea tomada por asalto (las prohibiciones enunciadas corresponden con los artículos 47, 23 letra g), 25 y 28).

Por otro lado, el Reglamento de La Haya de 1907 contiene una serie de disposiciones que contribuyen de forma directa a la protección de los bienes culturales, ${ }^{57}$ y los criterios dispuestos en las mismas para que un determinado objeto goce de la protección dispensada por el convenio es triple, a saber: en primer lugar, por las cualidades intrínsecas del objeto; en segundo lugar, en virtud de la institución a la que el objeto pertenece; y en tercer lugar, por la finalidad a la que el objeto está destinado. Por tanto, si bien la conjunción de dichos criterios pudiera parecer que concede una base sólida para su protección, lo cierto es que subsisten numerosas carencias. Estas carencias no tardaron en ser puestas de manifiesto, y así, durante la gran guerra, las formulas contenidas en el Reglamento de La Haya sobre la Protección de los Bienes Culturales se mostraron a toda luz insuficientes. Insuficiencias confirmadas posteriormente por las numerosas destrucciones de bienes culturales acontecidas durante la Segunda Guerra Mundial.

La deficiente situación en la materia hizo volver la mirada hacia una reglamentación especializada. Así, tras unos trabajos preparatorios, a iniciativa del gobierno de Italia, se convocó en 1954 una Conferencia Diplomática en La Haya en la que se abrió a la firma (del día 14 de mayo a 31 de diciembre de 1954) el Convenio para la protección de los bienes culturales en caso de conflicto armado, que entró en vigor el día 7 de agosto de 1956 (artículo 33.1 y 2).

57 Estas disposiciones son las siguientes: "En los sitios y bombardeos deberán tomarse todas las medidas necesarias para librar en cuanto sea posible, los edificios consagrados al culto, a las artes, a las ciencias y a la beneficencia, los monumentos históricos... siempre que no se utilicen al mismo tiempo esos edificios con un fin militar" (artículo 27.1). "Los bienes comunales, los de los establecimientos consagrados al culto, a la caridad y a la instrucción, a las artes y a las ciencias, aun pertenecientes al Estado, serán tratados como la propiedad privada" (artículo 56.1). Y "Toda apropiación, destrucción o daño intencionado de dichos establecimientos, de monumentos históricos, obras de arte y de ciencia están prohibidos y deben ser perseguidos" (artículo 56.2). 


\section{La noción de bienes culturales}

A diferencia de las numerosas y diferentes definiciones contempladas por los instrumentos internacionales hasta 1954 sobre la expresión "bienes culturales" (artículos 27.1 y 56.1 y 2 del Reglamento de La Haya de 1907), la codificación realizada en ese mismo año establece una noción uniforme de lo que debe entenderse por la misma. Dicho de otro modo, el Convenio para la Protección de los Bienes Culturales dispone una noción comprensible de todos los objetos susceptibles de beneficiarse de tal protección en caso de conflicto armado.

Según el artículo 1o., para los fines del referido convenio tendrán la consideración de bienes culturales, cualquiera que sea su origen y propietario:

a) Los bienes, muebles o inmuebles, que tengan una gran importancia para el patrimonio cultural de los pueblos, tales como los monumentos de arquitectura, de arte o de historia, religiosos o seculares, los campos arqueológi$\cos$, los grupos de construcciones que por su conjunto ofrezcan un gran interés histórico o artístico, las obras de arte, manuscritos, libros y otros objetos de interés histórico, artístico o arqueológico, así como las colecciones científicas y las colecciones importantes de libros, de archivos o de reproducciones de los bienes antes definidos; $b$ ) Los edificios cuyo destino principal y efectivo sea conservar y anteponer los bienes culturales muebles definidos en el apartado a), tales como los museos, las grandes bibliotecas, los depósitos de archivos, así como los refugios destinados a proteger en caso de conflicto armado los bienes culturales muebles definidos en al apartado a); c) Los centros que comprendan un número considerable de bienes culturales definidos en los apartados a) y b), que se denominan 'centros monumentales'.

De acuerdo con el precepto glosado, cabe concluir que la noción de "bien cultural" viene integrada por tres tipos diferentes de objetos: 1) Los objetos que revisten en sí mismos un valor artístico, científico, histórico o arqueológico. 2) Los objetos que, careciendo de los valores anteriores, sirvan para exponer o, en su caso, guardar los objetos que sí revistan tales valores (por ejemplo, museos, bibliotecas, etcétera). 3) Los objetos que estén integrados por otros objetos que en sí mismos tengan los valores anteriores (por ejemplo, ciudades, pueblos, etcétera: Florencia, Santillana del Mar, Cambridge, etcétera). 
Los bienes culturales protegidos comprenden el conjunto de conocimientos humanos de una persona, individualmente considerada, pueblo o época; esto es, el convenio tutela los bienes culturales resultado del cultivo de los referidos conocimientos mediante el ejercicio de las facultades intelectuales. Sin embargo, además de los objetos susceptibles de ser calificados como "bienes culturales", el convenio extiende su protección a otro tipo de objetos no englobados en la expresión anterior, pero que bajo determinadas circunstancias son beneficiarios de sus disposiciones, nos estamos refiriendo a los medios de transporte - convoyes - utilizados para trasladar bienes culturales, tanto en el interior de un país como en dirección a otro país, para su mejor protección. En definitiva, la convención es el primer instrumento convencional que "ha procedido a conceptualizar la noción de bienes culturales a través de su artículo 1o., letras a, b y c, en función de los caracteres intrínsecos del objeto, ya sea mueble o inmueble y con independencia de su origen y propietario". ${ }^{8}$

\section{La protección de los bienes culturales}

El artículo 2o. del convenio dispone que la protección de los bienes culturales "entraña la salvaguardia y el respeto de dichos bienes". La salvaguardia de los bienes culturales implica la adopción de las medidas apropiadas y necesarias, en tiempo de paz, para proteger dichos bienes de los efectos previsibles en caso de un conflicto armado (artículo 3o.), mientras que, por otro lado, el respeto supone una doble abstención consistente en su no utilización con finalidades militares y el no hacerlo objeto de actos hostiles (artículo 4.1).

Según lo enunciado en el párrafo anterior cabe realizar las siguientes afirmaciones: en primer lugar, en cuanto al ámbito temporal, la salvaguardia de los bienes culturales se realizará en tiempo de paz y, por tanto, ésta implica unas medidas de prevención. Por el contrario, la obligación de respeto de los referidos bienes coincide ya con el inicio de las hostilidades. En segundo lugar, con relación al capítulo de la responsabilidad en materia de protección, cabe distinguir entre la figura de la salvaguardia y la del respeto. Será responsable de la salvaguardia, según el artículo 3o., el Estado en cuyo territorio se encuentren situados los bienes objeto de protección ("bienes situados en su propio territorio"), ya que solamente

58 Paniagua Redondo, R., “La regulación jurídico internacional de los bienes culturales en caso de conflicto armado", Cuadernos de Política Jurídica, Barcelona, 1994, núm. 1, pp. 402 y ss. 
las autoridades de dicho Estado serán las competentes para adoptar las medidas que considere apropiadas.

En cuanto al respeto de los bienes culturales, la responsabilidad en este caso es compartida por las partes en conflicto. Así, mientras una de las partes se compromete a no "utilizar esos bienes, sus sistemas de protección y sus proximidades inmediatas para fines que pudieran exponer dichos bienes a destrucción o deterioro", la otra parte se compromete a no realizar ningún "acto de hostilidad respecto de tales bienes". A las obligaciones señaladas, cabe añadir otras de carácter específico como, por ejemplo, la de no tomar medidas de represalia contra los bienes culturales (artículo 4.4); la de no desligarse de las obligaciones estipuladas en el artículo 4o., con respecto a la otra parte, bajo el pretexto de que esta última no hubiera aplicado las medidas de salvaguardia establecidas en el artículo 3o. (artículo 4.5); la de introducir en tiempo de paz, en los reglamentos militares, disposiciones encaminadas a asegurar la observancia del convenio (artículo 7.1); etcétera.

En este contexto cabe citar el artículo 53 del Protocolo I Adicional a los Convenios de Ginebra, de 12 de agosto de 1949, relativo a la protección de las víctimas de los conflictos armados internacionales, pues dispone que:

Sin perjuicio de las disposiciones de la Convención de La Haya del 14 de mayo de 1954 para la protección de los bienes culturales en caso de conflicto armado y de otros instrumentos internacionales aplicables, queda prohibido: a) cometer actos de hostilidad dirigidos contra los monumentos históricos, obras de arte o lugares de culto que constituyen el patrimonio cultural o espiritual de los pueblos; $b$ ) utilizar tales bienes en apoyo del esfuerzo militar; $c$ ) hacer objeto de represalias a tales bienes.

El texto del precepto glosado aparece también recogido, exceptuando el apartado c, en el artículo 16, sobre la protección de los bienes culturales y de los lugares de culto, del Protocolo II Adicional a los Convenios de Ginebra, de 12 de agosto de 1949, relativo a la protección de las víctimas de los conflictos armados sin carácter internacional de 8 de junio de 1977.

En otro orden de cosas, cabe señalar la reserva contenida en el artículo 4.2, y que puede ser limitativa de cualquier medida de protección sobre los bienes culturales incluidos en la esfera de la denominada protección general (las reservas relativas a los bienes bajo protección especial apare- 
cen contempladas en los apartados 1 y 2 del artículo 11). El citado precepto dispone que las obligaciones de respeto a los bienes culturales "no podrán dejar de cumplirse más que en el caso de que una necesidad militar impida de manera imperativa su cumplimiento".

El propio convenio dispone que el cumplimiento de los compromisos derivados de sus disposiciones incumbe a los Estados parte, adoptando las medidas pertinentes (a modo de ejemplo, véase los artículos 3o., 4o., 7o. y 25). Asimismo, el artículo 28 viene referido a las sanciones:

Las Altas Partes contratantes se comprometen a tomar, dentro del marco de su sistema de derecho penal, todas las medidas necesarias para descubrir y castigar con sanciones penales o disciplinarias a las personas, cualquiera que sea su nacionalidad que hubieren cometido $u$ ordenado que se cometiera una infracción de la presente Convención.

A partir del texto transcrito puede establecerse el carácter general del precepto en cuestión, pues dispone el principio — general- de que no pueden infringirse o violarse de manera impune los compromisos adquiridos relativos a las medidas de protección de los bienes culturales.

\section{LA PROTECCIÓN DEL MEDIO AMBIENTE}

La preocupación por las acciones del ser humano sobre el medio ambiente alcanza las máximas cuotas con relación a un problema particular: las actividades militares y su innegable repercusión negativa en el hábitat humano. En relación a los medios y métodos de combate utilizados durante los conflictos armados, cabe decir que estos desencadenan una serie de efectos negativos sobre el medio ambiente. Estos efectos pueden venir determinados por a) la utilización de armas —o métodos — que de forma específica están pensadas para destruir el entorno ambiental (efectos directos) o $b$ ) por armas que de manera indirecta o refleja causan daños ambientales (efectos indirectos).

La utilización de determinados medios y métodos de combate está directamente vinculada con el deterioro del medio ambiente; así, el armamento usado durante la Primera y Segunda Guerras Mundiales, junto con el de los conflictos internacionales e internos posteriores, han afectado directamente la estabilidad del medio ambiente, alterando el equilibrio de los ecosistemas. Especial mención merece la Guerra de Vietnam, ya que 
en ella el medio ambiente fue seleccionado como objetivo de sistemática destrucción y, en este sentido, se utilizaron medios y métodos de combate encaminados a quebrar la relación hombre-naturaleza. ${ }^{59}$ Por tanto, la selección del medio ambiente como objetivo militar tenía por finalidad aislar al enemigo y, para ello, se utilizaron de forma sistemática e indiscriminada herbicidas, napalm, etcétera, que causaron alteraciones en los factores abióticos (climáticos, edáficos e hidrográficos).

Los medios y métodos de combate utilizados durante los diferentes conflictos armados pueden modificar el medio ambiente. Desde el punto de vista estratégico, el hombre puede llevar a cabo alteraciones de la atmósfera, de los océanos y de las masas continentales ${ }^{60}$ con el propósito de privar de la cobertura y apoyo a las fuerzas enemigas. Así, a modo de ejemplo, cabe citar la posibilidad de crear nubes, lluvia artificial, campos electromagnéticos, maremotos, aludes, corrimientos de tierras, huracanes, etcétera; posibilidades que un día pudieran convertir la "ciencia-ficción" en amarga realidad. Dicho de otro modo, los daños contra el medio ambiente pueden venir ocasionados por la llamada guerra geofísica ${ }^{61} \mathrm{o}$ manipulación deliberada de los procesos naturales, que puede provocar los fenómenos anteriormente enunciados. No es de extrañar, pues, que el derecho internacional humanitario contenga una serie de disposiciones tendentes a proteger el medio ambiente durante las contiendas armadas. Esta circunstancia responde al propio espíritu que inspira la propia existencia de esta normativa.

\section{La prohibición de medios de combate que provoquen una alteración del medio ambiente}

En la esfera de los convenios internacionales relativos al desarme, control y prohibición de armamentos, existen disposiciones dirigidas a tutelar el medio ambiente. Entre estos convenios cabe destacar el antiguo Protocolo de Ginebra, de 17 de junio de 1925, sobre prohibición del empleo en la guerra de gases asfixiantes, tóxicos o similares, o procedimien-

59 Falk, R., "Environmental warfare and ecocide. Facts, appraisal and proposals", RBDIR, pp. 1 y ss.

60 CCD/463, del 5 de agosto de 1975, Informe presentado por Canadá a la Conferencia del Comité de Desarme de las Naciones Unidas.

61 Sobre esta materia puede consultarse los comentarios de Kiss, A., "Les Protocoles Additionnels aux Conventions de Genève de 1977 et la protection de biens de l'environnement", en varios autores, Etudes et essais sur le droit international humanitaire et sur les principes de la Croix-Rouge en l'honneur de Jean Pictet, Ginebra, 1984, p. 187. 
tos análogos; el Protocolo I de Ginebra de 1977; el Convenio de 10 de abril de 1972 sobre la prohibición del desarrollo y almacenamiento de armas bacteriológicas y toxínicas y sobre su destrucción; el Convenio de 10 de diciembre de 1976 sobre prohibición de utilizar técnicas de modificación ambiental con fines militares u otros hostiles; y, por último, la Convención de 10 de abril de 1981 sobre prohibiciones o restricciones del empleo de ciertas armas convencionales que puedan considerarse excesivamente nocivas o de efectos indiscriminados.

En el ámbito de la prohibición de armas específicas contrarias a los principios generales, con incidencia en el medio ambiente, debemos destacar, por un lado, el Protocolo de Ginebra, de 17 de junio de 1925, relativo a la prohibición del empleo en la guerra de gases asfixiantes, tóxicos o similares o procedimientos análogos ${ }^{62} \mathrm{y}$, por otro, la Convención de $10 \mathrm{de}$ abril de 1981 sobre prohibiciones o restricciones del empleo de ciertas armas convencionales que puedan considerarse excesivamente nocivas $o$ de efectos indiscriminados.

Asimismo, cabe citar el conjunto de normas desarrolladas en la Conferencia Diplomática sobre la Reafirmación y el Desarrollo del Derecho Internacional Humanitario (1973-1978). Resultado de la misma fueron los protocolos adicionales I y II a los Convenios de Ginebra, de 12 de agosto de 1949, de fecha 8 de junio de 1977 relativos a la protección de las víctimas de los conflictos armados internacionales (Protocolo Adicional I) y a la protección de las víctimas de los conflictos armados sin carácter internacional (Protocolo Adicional II). En especial, como podrá apreciarse seguidamente, el Protocolo Adicional I contiene una referencia expresa a la protección del medio ambiente. Sin ánimo de llevar a cabo un examen pormenorizado de todas las disposiciones convencionales reseñadas, en las páginas que siguen se dispondrá una visión de carácter general de las mismas en orden a su posible aplicación en el conflicto armado del Golfo Pérsico.

El Protocolo de Ginebra de 17 de junio de 1925, según la resolución 2603 A (XXIV), de 16 de diciembre de 1969, de la Asamblea General, ${ }^{63}$ que ha adquirido rango consuetudinario según la doctrina mayoritaria, de-

62 Gaceta de fecha 6 de septiembre de 1929.

63 Documento A/9215, volumen I (Respecto de los derechos humanos en los conflictos armados. Normas de derecho internacional existentes sobre la prohibición o restricción del uso de determinadas armas. Estudio preparado por Secretaría). Esta resolución fue adoptada por 80 votos a favor, 3 en contra y 36 abstenciones. 
claró contrarias a las disposiciones de derecho internacional el empleo de los siguientes elementos: 1) Todo elemento químico (sustancias químicas sólidas, líquidas o gaseosas) de guerra cuyos efectos tóxicos puedan utilizarse de forma directa contra las personas, los animales y las plantas. 2) Todo elemento biológico (organismos vivos de cualquier naturaleza o material infeccioso derivado de los mismos) que produzca enfermedades o muerte en las personas, animales o plantas.

El Protocolo Adicional I a los Convenios de Ginebra, de 12 de agosto de 1949, tras reafirmar los principios generales relativos a la prohibición de los métodos y medios de combate indiscriminados, pérfidos y que causen daños superfluos y sufrimientos innecesarios, incorpora la protección del medio ambiente - en tiempo de conflicto armado - en los artículos 35.3 y 55. En el primero de los artículos citados en el párrafo anterior se estipula que "queda prohibido el empleo de métodos o medios de hacer la guerra que hayan sido concebidos para causar o de los que quepa prever que causen daños extensos, duraderos y graves al medio ambiente natural”. En el segundo se dispone que:

En la realización de la guerra se velará por la protección del medio ambiente natural contra daños extensos, duraderos y graves. Esta protección incluye la prohibición de emplear métodos o medios de hacer la guerra que hayan sido concebidos para causar o de los que quepa prever que causen tales daños al medio ambiente natural, comprometiendo así la salud o la supervivencia de la población.

Este precepto prohíbe los métodos y medios de guerra que ocasionen daños a la salud o a la supervivencia de la población. El término salud, en relación con el término supervivencia, debe entenderse en sentido amplio, pues con ella se pretende indicar las acciones de las cuales cabe esperar efectos muy graves (por ejemplo, aparición de defectos congénitos). Por otra parte, al término población no le sigue el adjetivo civil, y ello obedece al hecho de que la supervivencia es predicable de toda persona, con independencia de su condición de combatiente.

En todo caso también es aquí predicable, con relación a la protección del medio ambiente, en tanto que bien indispensable para la supervivencia humana, la Declaración de Estocolmo de junio de 1972, al disponer que "el hombre tiene el derecho fundamental a... el disfrute de condiciones de vida adecuadas, en un medio de calidad tal que le permita llevar una vida digna y gozar de bienestar, y tiene la solemne obligación de pro- 
tegerlo y mejorarlo para las generaciones presentes y futuras". Asimismo, la citada declaración proclama que "los dos aspectos del medio humano, el natural y el artificial, son esenciales para el bienestar del hombre y para el goce de los derechos humanos fundamentales, incluso el derecho a la vida misma".

A la vista de los preceptos glosados podemos llevar a término las siguientes observaciones, a saber: a) el artículo 35.3 contiene una norma básica de carácter general, relativa a los métodos y medios de combate, que tutela per se el medio ambiente; y $b$ ) el artículo 55 tutela el medio ambiente en tanto que indispensable para la supervivencia de las personas. En otras palabras, los artículos anteriormente transcritos tienen como principal objetivo impedir el empleo de métodos y medios que afecten al medio ambiente, incluyéndose tanto los métodos y medios encaminados de forma directa — premeditada - a causar daños ambientales como los métodos y medios "de los que sea previsible" que provoquen tales daños. A la luz de los citados preceptos, cabe considerar que la condena recae sobre todos los métodos y medios que ocasionen daños al medio ambiente, incluso aquéllos fruto de ataques contra objetivos militares.

Como la totalidad de las acciones bélicas causan daños en el medio ambiente, el legislador ha establecido una limitación al alcance de la prohibición contenida en el artículo 35.3 y, de esta forma, las acciones armadas que puedan causar daños que no sean extensos, duraderos ni graves quedan excluidos de la indicada prohibición. Cuando no concurran los criterios reseñados, no será de aplicación la prohibición del artículo comentado. La limitación del alcance de la prohibición viene dada por una interpretación a sensu contrario de la expresión "...causar o de los que quepa prever que causen daños extensos, duraderos y graves" 64 en rela-

64 Documento CDDH/III/GT/35 de 11 de marzo de 1975. Sobre este extremo, una primera redacción se establecía como criterio limitativo de esta prohibición: "la estabilidad de los ecosistemas". Empero, ante estos términos insuficientemente explícitos, se descartó tal criterio y, en su lugar, se incluyó el de "daños extensos, duraderos y graves". La Comisión III de la Conferencia indicó en su informe que "los tres elementos de la fórmula adoptada, el tiempo o duración de los daños o de la zona afectada y la gravedad o efectos perjudiciales de los daños para la población civil, fueron examinados detenidamente. Algunos representantes hablaron de 20 a 30 años como mínimo. Otros señalaron que destrucciones como las causadas en el campo de batalla en Francia, durante la I Guerra Mundial, habían de quedar fuera del alcance de la prohibición. El informe del Grupo Biotopo establece que no se trata de prohibir en este artículo los actos bélicos que puedan causar daños de menor duración al medio ambiente natural, como los bombardeos de artillería, y agrega que el periodo quizá sea de diez años o más. Sin embargo, es imposible decir con seguridad cuál sería la duración de este periodo. Pareció darse generalmente por supuesto que los daños en el campo de batalla, incidentales a la guerra convencional, no quedarán normalmente proscritos por esta disposición" (Doc. CDDH/215/REV. 1). 
ción a los medios y métodos de hacer la guerra. Así pues, cuando no concurran estos criterios, los métodos y medios de combate estarán al margen de la prohibición y, en consecuencia, no estarán proscritos.

En definitiva, el medio ambiente se configura como un objetivo "no legítimo" en la esfera del derecho internacional humanitario y, en concreto, en el presente instrumento convencional dispone la normativa de protección al medio ambiente en función de la protección dispensada en favor de la población, ya que la guerra ecológica tiene efectos indiscriminatorios que pueden afectar tanto a los combatientes como a la población civil.

Como es obvio, las contiendas armadas tienen por general un resultado dañoso para el medio ambiente, pues los campos y bosques son devastados en otras ocasiones, como en el caso que nos ocupa, el petróleo es derramado en el mar, etcétera. En ocasiones, estos casos son inevitables cuando se pretende destruir un determinado objetivo enemigo, pero cosa distinta es cuando con tal acción se pretende ocasionar un daño en el medio ambiental. Así, en el contexto indicado, la Convención de 10 de diciembre de 1976 sobre la prohibición del empleo de técnicas de modificación ambiental con fines militares u otros fines hostiles ${ }^{65}$ ha venido a impedir el uso indiscriminado e intencionado de métodos no convencionales que ocasionen daños medioambientales.

La convención estructura en torno a diez artículos la prohibición de técnicas de guerra ecológica. No obstante, la prohibición dispuesta solamente podrá ser efectiva cuando concurran los requisitos establecidos en los artículos primero y segundo. Veamos, pues, seguidamente su contenido.

En primer lugar, cada Estado parte se compromete a la no utilización de técnicas de modificación ambiental con fines militares u otros fines hostiles como medio dirigido a causar la destrucción, daños o perjuicios a otro Estado parte. Así pues, la prohibición viene referida a la utilización ${ }^{66}$

65 Resolución 31/72, de 10 de diciembre de 1976, de la Asamblea General (aprobada por 96 votos a favor, 8 en contra y 30 abstenciones. Kuwait votó en contra de la misma). BOE de 22 de noviembre de 1978.

66 En todo caso, la prohibición sólo afecta las utilizaciones que tengan efectos graves, duraderos y extensos. Estos términos, según consta en el Documento CCD/PV.691, serán interpretados de acuerdo con la convención como sigue: que entrañan un grave e importante perjuicio o perturbación para la vida humana, los recursos naturales y económicos y otros aspectos del patrimonio (grave); que tienen un periodo de duración de meses o aproximadamente una estación del año (duración); y, por último, que abarcan una región de varios centenares de kilómetros cuadrados (extensos). No obstante, esta interpretación, a pesar de estar formulada en un documento de la Conferencia, no fue recogida en el texto final de la convención. 
de técnicas de modificación ambientales con fines bélicos y hostiles; esto es, a su utilización como arma en casos de conflicto armado o, en ausencia de estos, con finalidades meramente hostiles.

En segundo lugar, debe tratarse de técnicas cuya finalidad consista en alterar, mediante una manipulación voluntaria — deliberada- de los procesos naturales, la dinámica, composición o estructura de la Tierra, incluida su biótica, su litosfera, su hidrosfera y su atmósfera, o el espacio ultraterrestre. ${ }^{67}$ En tercer lugar, la convención, a tenor del apartado primero del artículo III, no impide "la utilización de técnicas de modificación ambiental con fines pacíficos, ni contravendrán los principios generalmente reconocidos y las normas aplicables del derecho internacional relativas a esa utilización". Asimismo, el apartado segundo del precepto glosado dispone que:

Los Estados parte se comprometen a facilitar el intercambio más amplio posible de información científica y tecnológica sobre la utilización de técnicas de modificación ambiental con fines pacíficos, y tienen derecho a participar en ese intercambio. Los Estados parte que puedan hacerlo contribuirán, individual o conjuntamente con otros Estados u organizaciones internacionales, a la cooperación económica y científica internacional en la preservación, mejora y utilización del medio ambiente con fines pacíficos, teniendo debidamente en cuenta las necesidades de las regiones en desarrollo del mundo.

Como puede observarse, el precepto transcrito contiene una serie de afirmaciones muy "abstractas", sin disponer las pautas a seguir en la materia por parte de los Estados y, por ello, la doctrina ha llegado a afirmar que:

Hubiere sido mejor no decir nada o, por el contrario, entrar en detalles, obligarse a hacer públicas las investigaciones y todas las actividades pacíficas, garantizar que las actividades con fines pacíficos no se llevarían a cabo con fines hostiles, recordar y precisar la responsabilidad de cada Estado parte, por razón de los daños o perjuicios que podría causar a otra parte, utilizan-

67 "As used article I, the term environmental modification techniques refers to any technique for changing - through the deliberate manipulation of natural processes - the dynamics, composition or structure of the Earth, including its biota, lithosphere, hydrosphere and atmosphere, or of outer space" (artículo II). 
do técnicas de modificación con fines pacíficos, lo que impediría que las actividades prohibidas fueran camufladas en actividades pacíficas. ${ }^{68}$

En este punto, podemos concluir este breve examen afirmando que la convención viene referida a la manipulación deliberada de los procesos naturales, ${ }^{69}$ y por lo tanto no afectará a las consecuencias que sobre el medio ambiente causen otros medios de combate clásicos u armas de destrucción masiva.

\section{La protección dispensada en favor del medio ambiente en tiempo de paz y los conflictos armados}

¿Son las reglas generales de protección del medio ambiente aplicables en tiempo de guerra? El medio ambiente es un bien susceptible de tutela jurídica y, por ello, tanto su protección como preservación debe ser considerada no sólo desde la perspectiva de las disposiciones propias del derecho humanitario sino también desde las reglas generales del derecho internacional propias del tiempo de paz, cuyo objetivo es conservar y mejorar dicho medio.

El punto de partida para el examen de las reglas generales de protección del medio ambiente, y su aplicación en caso de guerra, es el informe titulado "La protección del medio ambiente en tiempo de conflicto armado", elaborado por un grupo de especialistas tanto en derecho internacional humanitario como en derecho internacional del medio ambiente. ${ }^{70}$

68 Fisscher, G., "La Convention sur l'interdiction d'utiliser des techniques de modification de l'environement à des fins hostiles", en AFDI, 1977, p. 834. Sola, M., Protección..., cit., p. 249 (sic).

69 Documento CCD/520, anexo A. Según consta en este documento, "el Comité entiende que los ejemplos siguientes son indicativos de los fenómenos que podrían causar la utilización de las técnicas de modificación del medio ambiente, que se definen en el artículo II de la convención: terremotos, maremotos, perturbación del equilibrio ecológico de una región, modificación de las pautas del clima (nubosidad, precipitaciones, ciclones de diversos tipos y tormentas huracanadas), modificaciones de las corrientes oceánicas, modificaciones del estado de la capa de ozono y modificación del estado de la biosfera. Se entiende, asimismo, que todos los fenómenos anteriormente mencionados, cuando se producen como resultado de la utilización de técnicas de modificación del medio ambiente con fines militares u otros fines hostiles, ocasionarían, o sería razonable esperar que ocasionaran daños, destrucción o perjuicios difundidos, duraderos o graves... Se reconoce, además, que la lista de ejemplos establecida anteriormente, no es exhaustiva".

70 Documento SJ/110/85. El grupo de trabajo estaba dirigido por Karl Heinz Narjes, miembro de la Comisión de la Comunidad Europea, e integrado por los profesores Alexandre Kiss, Antonio Cassese, Michael Bothe, Frits Kalshoven, Kennet Simmonds y Jean Salmon. Informe en el que se analiza los posibles problemas relativos a la prevención y reparación de los daños ocasionados sobre el medio ambiente por las operaciones militares llevadas a cabo durante el transcurso de los conflictos armados. A partir del citado informe cabe estructurar las reglas generales relativas a la protección 
El principio fundamental que rige en la materia, a partir de ciertas reglas tradicionales sólidamente establecidas en derecho internacional, es que los Estados no pueden utilizar su territorio para causar daños medioambientales a otros Estados. A partir de este principio, recogido tanto en decisiones judiciales como arbitrales, ${ }^{71}$ cabe observar la existencia de una serie de obligaciones generales de los Estados en la protección del medio ambiente (por ejemplo, no contaminar, prevenir, cooperar, reparar, etcétera).

Ahora bien, el citado principio no se limita única y exclusivamente a prohibir los posibles daños medioambientales causados a otros Estados, sino que el mismo está dirigido a proteger aquellos espacios que se encuentran más allá de los límites territoriales de los Estados; en otras palabras, los Estados tienen la obligación general de proteger y preservar los espacios no sometidos a la soberanía territorial de ningún Estado; ${ }^{72}$ esto es, tienen la obligación de asegurar que las actividades por ellos realizadas no perjudiquen al medio de zonas situadas fuera de toda jurisdicción nacional.

La obligación general encuentra su máxima expresión convencional en el artículo 192 en la Convención de las Naciones Unidas, firmada en Montego Bay el 10 de diciembre de 1982, sobre el derecho del mar, al

del medio ambiente en torno a la obligación de los Estados de no causar daños ambientales a otros Estados, por un lado, y la obligación de respetar el medio ambiente en general, por otro.

71 CIJ, Recueil..., cit., nota 17, p. 22. Sentencia de 9 de abril de 1949 (Estrecho de Corfú). "L'obligation, pour un Etat, de ne pas laisser utiliser son territorire aux fins d'actes contraires aux droits d'autres Etats". En todo caso, la obligación derivada del uso no perjudicial del territorio fue proclamada con anterioridad por Max Huber en el laudo del Asunto Isla de Palmas: "La souverainité implique le droit exclusif d'exercer les activités étatiques. Ce droit a pour corollaire un devoir: l'obligation de protéger, à l'intérieur du territoire, les droits des autres Etats, en particulier leur droit à l'intégrité et à l'inviolabilité en temps de paix et en temps de guerre, ainsi que les droits que chaque Etat peut réclamer pour ses nationaux en territoire étranger" (RSA, II, p. 829). Asimismo, esta obligación es la base de la decisión arbitral dictada en el Asunto Fundición de Trail al afirmar que "d'après les principes du Droit international... aucun Etat n'a le droit d'user de son territoire ou d'en permettre l'usage de manière que des fumées provoquent un préjudice sur le territoire d'un autre Etat ou aux propriétes des personnes qui s'y trouvent, s'il s'agit de conséquences sérieuses et si la préjudice est prouvé par des preuves claires et convaicantes" (11 de marzo de 1940, RSA, III, p. 1965). Sobre este último asunto, Madders, K., "Trail Smelter Case", Encyclopedia of Public International Law, vol. II, pp. 270 y ss.

72 Así, por ejemplo, a nivel convencional cabe citar el Convenio de Ginebra, de 13 de noviembre de 1979, sobre contaminación transfronteriza de la atmósfera a larga distancia, que tiene por objetivo limitar y reducir la contaminación atmosférica. Sobre la protección de la atmósfera se pueden consultar las siguientes obras, Kiss, A., "La protection de l'atmosphère: un exemple de mondialisation des problèmes", AFDI, 1988, pp. 701 y ss.; y Lammers, J., Report on aspects of long-distance air pollution, París, 1984. 
disponer que "los Estados tienen la obligación de proteger y preservar el medio marino"; esto es, el citado precepto dispone una norma de carácter general aplicable a todos los espacios marinos. A partir del citado precepto se dispone la obligación de que los Estados adopten todas las medidas “...que sean necesarias para prevenir, reducir y controlar la contaminación del medio marino procedente de cualquier fuente, utilizando a estos efectos los medios más viables de que dispongan y en la medida de sus posibilidades" (artículo 194.1). Añadiendo seguidamente la obligación de que los Estados tomen todas las medidas necesarias:

...Para garantizar que las actividades bajo su jurisdicción o control se realicen de tal forma que no causen perjuicios por contaminación a otros Estados y su medio ambiente, y que la contaminación causada por incidentes o actividades bajo su jurisdicción o control no se extienda más allá de las zonas donde ejercen derechos de soberanía de conformidad con la presente Convención (artículo 194.2).

En consecuencia, "se afirma así en el derecho positivo el principio general de no dañar al medio marino en cuanto tal". ${ }^{73}$

La obligación de los Estados de no causar daños o perjuicios por contaminación más allá de los límites de su competencia territorial aparece confirmada en el principio 21 de la Declaración de Estocolmo de 16 de junio de 1972. Según el citado principio: ${ }^{74}$

De conformidad con la Carta de las Naciones Unidas y con los principios del Derecho internacional, los Estados tienen el derecho soberano de explotar sus propios recursos en aplicación de su propia política ambiental y la obligación de asegurar que las actividades que se lleven a cabo dentro de su jurisdicción o bajo su control no perjudiquen al medio de otros Estados o de zonas situadas fuera de toda jurisdicción nacional.

En definitiva, el contenido del principio glosado es generalmente reconocido actualmente como "l'expression d'une régle devenue la base coutumière du droit international de l'environnement". ${ }^{75}$ Por tanto, cabe concluir afirmando que la obligación de los Estados de no causar daños o

73 Mariño Menéndez, F., La protección..., cit., p. 495 (sic).

74 En virtud del citado principio se adoptaron el Convenio de Viena para la Protección de la Capa de Ozono, de 22 de marzo de 1985, y el Protocolo de Montreal sobre Sustancias que Agotan la Capa de Ozono, de 16 de septiembre de 1987.

75 Al respecto, Kiss, A., Droit international de l'environnement, París, 1989, p. 34. 
perjuicios al medio existente más allá del espacio sometido a su soberanía constituye una regla de derecho consuetudinario.

En este punto, una vez establecido el marco general, puede observarse la existencia de una obligación para los Estados de no perjudicar o causar daños al medio de otros Estados o al de zonas situadas fuera de toda jurisdicción nacional. Obligación que deben respetar también en tiempo de guerra; esto es, la existencia de un conflicto armado no implica una liberación de tal obligación para los Estados beligerantes: las partes en guerra deberán abstenerse de cometer daños al medio de otros Estados y al de las zonas no sometidas a jurisdicción nacional.

\section{LA APLICACIÓN DEL DERECHO INTERNACIONAL HUMANITARIO}

Los Convenios de Ginebra tienen por finalidad impedir que los Estados rehuyan sus responsabilidades, ya que "ninguna Parte Contratante podrá exonerarse, ni exonerar a otra Parte Contratante, de las responsabilidades en que haya incurrido ella misma u otra Parte Contratante a causa de las infracciones previstas en el artículo anterior" (artículos 51, 52, 131 y 148 comunes a los convenios). Por otro lado, de conformidad con el artículo 80.1 del Protocolo I de 1977, la aplicación de las normas internacionales humanitarias corresponde a las partes en conflicto y, en este sentido, deberán adoptar las medidas necesarias para el cumplimiento de las obligaciones que les incumban.

A la luz de lo dispuesto por los preceptos transcritos en páginas anteriores, puede observarse que los Convenios de Ginebra, así como sus protocolos, establecen únicamente los tipos delictivos, ${ }^{76}$ pues no hacen referencia alguna a la determinación de las penas, correspondiendo su imposición a los sistemas penales nacionales. En el caso particular del

76 En la Convención sobre la Imprescriptibilidad de los Crímenes de Guerra y de los Crímenes de Lesa Humanidad, adoptada por la Asamblea General en su resolución 2391 (XXIII), de 26 de noviembre de 1968 (en vigor desde el 11 de noviembre de 1970, de conformidad con el artículo VIII) se establece que son imprescriptibles "los crímenes de guerra según la definición dada en el Estatuto del Tribunal Militar Internacional de Nuremberg, de 8 de agosto de 1945, y confirmada por las resoluciones de la Asamblea General de las Naciones Unidas 3 (I) de 23 de febrero de 1946 y 95 (I) de 11 de diciembre de 1946, sobre todo la infracciones graves enumeradas en los Convenios de Ginebra de 12 de agosto de 1949 para la protección de las víctimas de la guerra" (artículo 1o., letra a). Así pues, las infracciones graves de los convenios y del Protocolo I adicional son imprescriptibles y punibles en todo momento y lugar. 
Estado español, corresponderá al Código Penal aprobado por la Ley Orgánica 10/1995 de 23 de noviembre. ${ }^{77}$

Al tratar de los delitos contra las personas y bienes protegidos en caso de conflicto armado, las penas de prisión dispuestas por el Código Penal vienen referidas a los diferentes actos, perpetrados sobre las personas o bienes protegidos, calificados por los Convenios de Ginebra y el Protocolo I Adicional como infracciones graves, oscilando las penas de prisión, según los delitos, de cuatro a ocho años (artículo 609), de diez a quince años (artículos 610 y 611), de tres a siete años (artículo 612) y de cuatro a seis años (artículo 613), sin perjuicio de la pena que corresponda por los resultados producidos (artículos 609, 610, 611 y 612). Los restantes actos o infracciones cometidas, con ocasión de un conflicto armado, contra las personas protegidas y los bienes culturales, tendrán una pena de prisión de seis meses a dos años (artículo 614).

Asimismo, el legislador estatal ha establecido que en el caso de que los referidos delitos fueran cometidos por una autoridad o funcionario público, se le impondrá además de la pena señalada, la inhabilitación absoluta de diez a veinte años; si fuese un particular, los órganos judiciales podrán imponerle la inhabilitación especial para empleo o cargo público de uno a diez años (artículo 616 del Código Penal). Además, la provocación, conspiración y proposición para la ejecución de este delito se castigará con la pena inferior en uno o dos grados a la que correspondería al mismo (artículo 615).

\section{EL CONTROL DE LA APLICACIÓN DEL DERECHO INTERNACIONAL HUMANITARIO}

El control de la aplicación de las normas internacionales humanitarias puede llevarse a cabo mediante la designación de potencias protectoras y el establecimiento de una Comisión Internacional de Encuesta.

\section{Las potencias protectoras}

La figura de las potencias protectoras aparece contemplado en los cuatro Convenios de Ginebra de 1949 (artículos 8o., 80., 80. y 9o., respectivamente) y en el Protocolo I de 1977 (artículo 5o.). Las potencias

77 Paniagua Redondo, R. y Acosta Estévez, J., "El (nuevo) Código Penal y los delitos contra las personas y bienes protegidos en casos de conflicto armado", Anales (UNED), 1993. 
protectoras son Estados que no son partes en un conflicto armado y que tienen por objetivo salvaguardar los intereses de las partes beligerantes.

Desde el inicio del conflicto armado, las partes beligerantes tienen el deber de asegurar la supervisión y ejecución de los Convenios de Ginebra y del Protocolo I mediante la aplicación del sistema de potencias protectoras. Este deber conlleva la designación y aceptación de dichas potencias. Al respecto, cada parte beligerante designará sin demora una potencia protectora y autorizará la actividad de una potencia protectora que, designada por la otra parte beligerante, haya sido aceptada como tal por ella. En el supuesto de que no haya habido designación o aceptación de potencia protectora, se aplicará el mecanismo previsto en los apartados 3 y 4 del artículo 5o. del Protocolo I para la designación de la potencia protectora.

Para la consecución del objetivo perseguido, las potencias protectoras podrán designar, además de su personal diplomático o consular, delegados entre sus propios nacionales o entre los de otros Estados neutrales; en todo caso, estos delegados deberán quedar sometidos a la aprobación del Estado cerca del cual han de ejercer su misión.

Los Estados beligerantes facilitarán, en la mayor medida posible, la tarea de los representantes o delegados de las potencias protectoras. Ahora bien, éstos no deberán rebasar los límites de su misión y habrán de tener especialmente en cuenta las necesidades de seguridad del Estado en donde ejercen sus funciones. Su actividad solamente podrá ser restringida excepcional y transitoriamente por exigencias militares imperiosas.

\section{La Comisión Internacional de Encuesta}

El artículo 90 del Protocolo I contempla la constitución de una Comisión Internacional de Encuesta, compuesta por quince miembros de alta reputación moral y de reconocida imparcialidad, que actuarán a título personal y ejercerán su mandato hasta la elección de nuevos miembros.

La comisión tendrá competencia para: 1) proceder a una investigación sobre cualquier hecho que haya sido alegado como infracción grave, tal como se define en los convenios o en el Protocolo I, y 2) facilitar, mediante sus buenos oficios, el retorno a una actitud de respeto de los convenios y del Protocolo I. En otros casos, la comisión procederá a una investigación a petición de una parte en conflicto únicamente con el consentimiento de la otra u otras partes interesadas. 